\title{
The LAT Story: A Tale of Cooperativity, Coordination, and Choreography
}

\author{
Lakshmi Balagopalan, Nathan P. Coussens, Eilon Sherman, Lawrence E. Samelson, \\ and Connie L. Sommers
}

LCMB/CCR/NCI/NIH, Bethesda, Maryland 20892-4256

Correspondence: samelson@helix.nih.gov

\begin{abstract}
The adapter molecule LAT is a nucleating site for multiprotein signaling complexes that are vital for the function and differentiation of T cells. Extensive investigation of LAT in multiple experimental systems has led to an integrated understanding of the formation, composition, regulation, dynamic movement, and function of LAT-nucleated signaling complexes. This review discusses interactions of signaling molecules that bind directly or indirectly to LAT and the role of cooperativity in stabilizing LAT-nucleated signaling complexes. In addition, it focuses on how imaging studies visualize signaling assemblies as signaling clusters and demonstrate their dynamic nature and cellular fate. Finally, this review explores the function of LAT based on the interpretation of mouse models using various LAT mutants.
\end{abstract}

\section{INTRODUCTION}

inker for activation of $\mathrm{T}$ cells (LAT) was Lcloned a little more than a decade ago. Since then, a multitude of studies have revealed that LAT-based complexes catalyze critical TCRmediated signaling reactions and enable activation of multiple downstream pathways that control almost all TCR-initiated cellular responses. This article spotlights diverse experimental systems in which LAT function has been studied. Information gained from these studies has led to an integrated understanding of the cellular function of LAT.

\section{Cloning and Structural Features of LAT}

The study of the tyrosine phosphorylation of proteins induced by immunoreceptor and growth factor receptor stimulation has led to critical insights into mechanisms of signal transduction (Hunter 2009). Early studies showed that a number of proteins became phosphorylated on tyrosine residues following TCR stimulation in Jurkat T-cell leukemia cells and in normal T cells (June et al. 1990). Many of these proteins, such as ZAP-70, SLP-76, and PLC- $\gamma 1$, have been shown to be critical elements for TCR signal transduction (Kane et al. 2000). A protein with an apparent molecular weight of 36 and $38 \mathrm{kDa}$ was also prominently phosphorylated on tyrosine in response to TCR stimulation. Several preliminary studies showed that this protein, known then as pp36/38, was membrane-associated and capable of binding SH2 domains of Grb2, Grap, PLC- $\gamma 1$, and the p85 subunit of phosphatidylinositol 3-kinase (PI3K) (June et al. 1990; Gilliland et al. 1992; Buday et al. 1994; Sieh et al. 1994; Fukazawa

Editors: Lawrence E. Samelson and Andrey Shaw

Additional Perspectives on Immunoreceptor Signaling available at www.cshperspectives.org

Copyright (C) 2010 Cold Spring Harbor Laboratory Press; all rights reserved; doi: 10.1101/cshperspect.a005512

Cite this article as Cold Spring Harb Perspect Biol 2010;2:a005512 
L. Balagopalan et al.

et al. 1995a; Trub et al. 1997). Although pp36/ 38 was first observed in 1990, it proved challenging to isolate. It was not until 1998 that the Samelson laboratory cloned it by large-scale membrane purification of activated Jurkat cells (Zhang et al. 1998a). Shortly after, Weber et al. reported the cloning of the rat and human proteins from thymocytes (Weber et al. 1998). The Samelson lab named the protein product LAT, for Linker for Activation of $\underline{T}$ cells based on several of its characteristics. LAT is expressed in T cells and in a limited number of other immune cell types (mast cells, natural killer cells, megakaryocytes, platelets, and immature B cells) (Facchetti et al. 1999; Oya et al. 2003). Furthermore, as detailed below, LAT facilitates the recruitment of many signaling proteins to the plasma membrane where it links receptors, tyrosine kinases and their substrates and other effector molecules together, functioning as a critical activator of $\mathrm{T}$ cells.

Sequencing of human LAT cDNA identified an open reading frame encoding a protein predicted to contain 233 amino acids. The mouse and rat homologs of LAT encode 242 and 241 amino acid proteins, respectively, and have $65 \%-70 \%$ sequence identity with human LAT. The predicted molecular mass of LAT is $25 \mathrm{kDa}$. However, LAT is strikingly acidic and its charge may account for slower migration on SDS-PAGE leading to its apparent molecular weight of $36 / 38 \mathrm{kDa}$. Structurally, LAT is a type III transmembrane protein. It has a cytosolic carboxyl terminus (like type I proteins), but lacks a signal sequence (Brown 2006). LAT contains only a four-amino-acid extracellular region, a single transmembrane spanning region and a long intracellular region with no apparent intrinsic enzymatic activity or protein-protein interaction domains. However, consistent with the strong tyrosine phosphorylation of pp36/38 observed upon TCR stimulation, the intracellular domain of LAT contains nine tyrosines conserved between humans, mice, and rats. Examination of LAT amino-acid sequence also revealed two conserved cysteine residues (C26 and C29 in human LAT), which are located adjacent to the predicted transmembrane domain of LAT and are subject to posttranslational palmitoylation (Zhang et al. 1998b). Palmitoylation of LAT is necessary for LAT function (Lin et al. 1999; Zhang et al. 1999a), but the role of palmitoylation in specific localization of LAT within the plasma membrane has been controversial and is discussed below. More recently, studies have shown that LAT is also subject to ubiquitylation (Brignatz et al. 2005; Balagopalan et al. 2007), a modification that might be involved in activation-induced internalization of LAT complexes and regulation of LAT protein levels. Inspection of LAT amino acid sequence reveals two lysines (K52 and K204 in human LAT), which might serve as potential sites for ubiquitylation. A schematic of LAT structural features is shown in Figure 1A.

\section{Palmitoylation and Membrane Localization of LAT}

Palmitoylation is thought to enhance the association of transmembrane proteins, including LAT, with regions of membrane heterogeneity sometimes called lipid rafts (Brown 2006). In $\mathrm{T}$ cells, several signaling molecules in addition to LAT, including the TCR, Lck, Vav, Grb2, PLC- $\gamma 1$, and Ras are associated with lipid rafts (Brdicka et al. 1998; Montixi et al. 1998; Zhang et al. 1998b). Thus, rafts have been postulated to function as important platforms to initiate signaling cascades (Brown and London 1998). However, the physiological role of this membrane heterogeneity has been intensely debated (Munro 2003; He and Marguet 2008; Kenworthy 2008). Reflecting this debate, the importance of raft localization for LAT function has been controversial.

Early studies reported that a cysteinemutated form of LAT was not recruited to lipid rafts and could not reconstitute signaling in a LAT-deficient Jurkat cell line, leading to the conclusion that localization of LAT to lipid rafts was required for its function (Lin et al. 1999; Zhang et al. 1999a). However, more recent studies indicated that palmitoylation of LAT was required for the protein to be transported efficiently to the plasma membrane and that, in the absence of palmitoylation, LAT was 
A

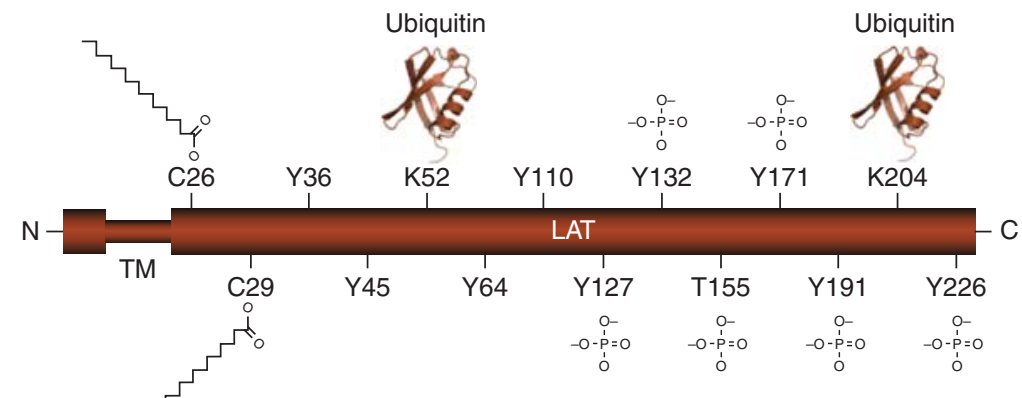

B

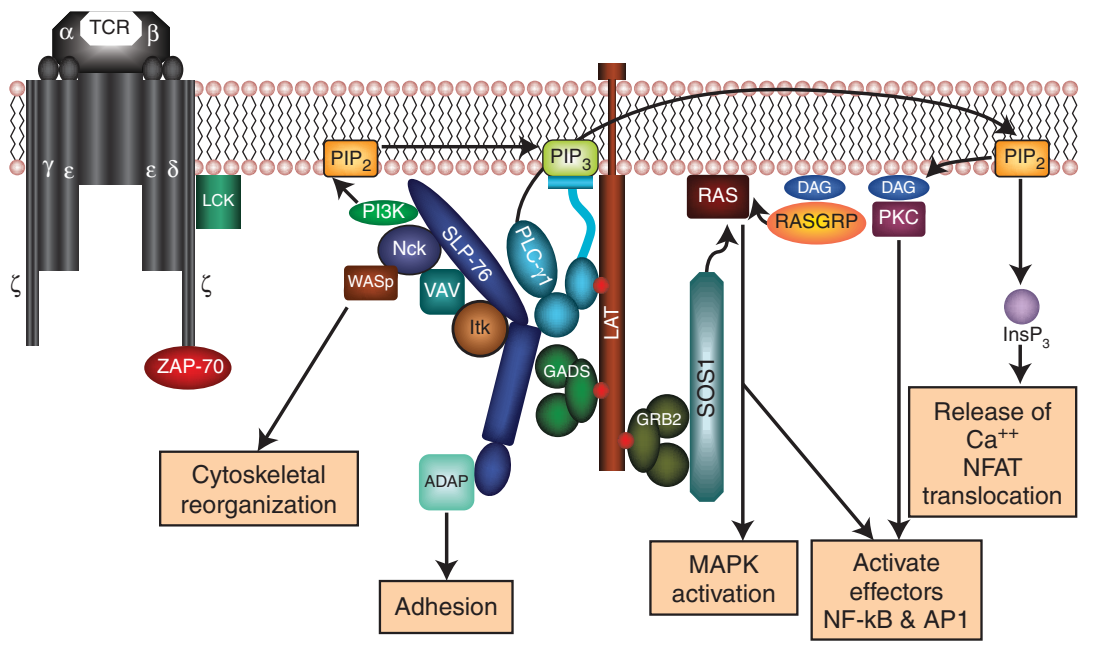

Figure 1. LAT in TCR signal transduction. (A) Human LAT is a 233 amino-acid type III transmembrane protein with four extracellular amino acids, a single transmembrane region, and a cytosolic region that undergoes multiple posttranslational modifications. Modifications include palmitoylation at cysteine residues C26 and C29 and possible ubiquitylation at lysine residues K52 and K204 (Ubiquitin [Protein Data Bank ID 1UBQ] is represented as a ribbon diagram generated with the program PyMOL). Nine tyrosine residues are conserved between human and mouse LAT sequences, five of which have been shown to undergo phosphorylation (Y127, Y132, Y171, Y191, and Y226). Threonine 155 is also phosphorylated by Erk. (B) Ligation of the TCR induces tyrosine phosphorylation of numerous adapter and effector proteins leading to the activation of multiple signaling pathways important for gene transcription, cytoskeletal reorganization, and cell adhesion. LAT is central to this process by nucleating multiprotein signaling complexes that are important for enzyme activation and signal propagation.

susceptible to degradation (Gringhuis et al. 2000; Hundt et al. 2006; Tanimura et al. 2006; Hundt et al. 2009). Furthermore, LAT fusion proteins targeted to nonraft domains reconstituted LAT function in LAT-deficient Jurkat cells or LAT-deficient mice (Zhu et al. 2005; Hundt et al. 2009). These data raise the possibility that the signaling defects initially observed for a LAT palmitoylation mutant might result from defects in plasma membrane transport, rather than displacement from lipid domains.
Collectively, these data suggest that targeting of LAT to the plasma membrane of the cell is sufficient for its function, regardless of specific localization within the membrane.

\section{LAT is Central to T-Cell Signaling}

The essential role of LAT in T-cell signal transduction has been demonstrated in a variety of experimental settings. Initial work showed that Jurkat T-cell lines lacking expression of LAT 
L. Balagopalan et al.

were defective in several TCR-mediated signaling events including $\mathrm{Ca}^{2+}$ mobilization, Ras activation, CD69 expression, Erk activation, and AP-1/NFAT-directed gene transcription (Finco et al. 1998; Zhang et al. 1999a; Samelson 2002). Reintroduction of LAT rescued all these defects indicating that LAT is indispensable for T-cell activation via the TCR. Soon after, targeted disruption of the LAT gene in mice revealed a requirement for LAT in T-cell development. Animals that lack LAT exhibited an early arrest of thymocyte development and no mature $\alpha \beta$ $\mathrm{T}$ cells were found in their peripheral lymphoid organs (Zhang et al. 1999b). Additional reports highlighted the adapter function of LAT by showing that multiple signaling proteins bind phosphorylated LAT once the TCR is engaged. These LAT binding proteins subsequently attract multiple cytosolic protein partners and further waves of tyrosine phosphorylation and protein interactions occur. Thus LAT functions as a crucial nucleating site at the plasma membrane for multiprotein signaling complexes.

\section{LAT AS A NUCLEATION CENTER FOR T-CELL SIGNAL TRANSDUCTION}

LAT functions as a classic adapter protein by facilitating the formation of multiprotein complexes (Fig. 1B). Numerous studies have investigated the composition of LAT-nucleated complexes. This section will describe the direct and indirect associations of enzymes, adapters and effectors to LAT and provide insights into how these interactions lead to activation of specific intracellular pathways.

\section{Phosphorylation of LAT}

LAT is rapidly phosphorylated on tyrosine residues upon TCR engagement. Though a full understanding of how the kinases phosphorylate the individual tyrosines on LAT in vivo remains unresolved, overexpression and in vitro studies have implicated primarily ZAP-70, but also Lck and Itk in LAT phosphorylation (Zhang et al. 1998a; Paz et al. 2001; Perez-Villar et al. 2002; Jiang and Cheng 2007). Even less is known about the phosphatases that dephosphorylate
LAT, however CD148 has been implicated (Baker et al. 2001).

\section{PLC- $\gamma 1$ Binds Y132 of LAT and Mediates Transcriptional Activation in T Cells}

The phospholipase PLC- $\gamma 1$ is an important mediator of TCR signal transduction. PLC- $\gamma 1$ hydrolyzes phosphatidylinositol 4,5-bisphosphate $\left(\mathrm{PIP}_{2}\right)$ to produce inositol 1,4,5-trisphosphate $\left(\mathrm{IP}_{3}\right)$ and diacylglycerol (DAG) (Rhee and Bae 1997). DAG stimulates the Ras activator RasGrp (Ras guanyl-releasing protein) and the serine/threonine kinase PKC (protein kinase C). The production of $\mathrm{IP}_{3}$ by PLC- $\gamma 1$ promotes the release of stored intracellular calcium, causing an extracellular $\mathrm{Ca}^{2+}$ influx and a sustained increase in intracellular $\mathrm{Ca}^{2+}$ concentrations important for NFAT activation (Oh-hora 2009).

PLC- $\gamma 1$ is a multidomain enzyme that includes a pleckstrin homology $(\mathrm{PH})$ domain that can bind membrane phosphoinositides, two phosphotyrosine-binding SH2 (src homology 2) domains and an SH3 (src homology 3) domain, which binds specific proline-rich sequences. PLC- $\gamma 1$ binding to LAT was observed even before LAT was cloned and was shown to be dependent on the amino-terminal SH2 domain of PLC- $\gamma 1$ (Gilliland et al. 1992; Weber et al. 1992; Stoica et al. 1998; Irvin et al. 2000). Interaction with LAT was shown to be required for both PLC- $\gamma 1$ activation and localization near its substrate $\mathrm{PIP}_{2}$ at the plasma membrane (Zhang et al. 1999a; Zhang et al. 2000; Lin and Weiss 2001). Subsequently, the amino-terminal SH2 domain of PLC- $\gamma 1$ was shown to bind phosphorylated LAT Y132 with high affinity (Paz et al. 2001; Houtman et al. 2004). Furthermore, a single $\mathrm{Y} 132 \mathrm{~F}$ mutation abolished the association between LAT and PLC- $\gamma 1$ in Jurkat $\mathrm{T}$ cells (Zhang et al. 2000). However, further experimentation revealed that full PLC- $\gamma 1$ activation required additional binding interactions to LAT and LAT-associated molecules.

Several studies showed that LAT Y171 and Y191 also contributed to PLC- $\gamma 1$ binding and that all four distal LAT tyrosines (132, 171, 191, and 226) were required for optimal PLC$\gamma 1$ phosphorylation and downstream calcium 
influx (Zhang et al. 2000; Lin and Weiss 2001; Zhu et al. 2003). The adapter protein SLP-76 (that binds to Gads, which binds to LAT Y171 and Y191) was also shown to be required for PLC- $\gamma 1$ activation (Yablonski et al. 1998). Braiman and colleagues demonstrated that multiple domains of PLC- $\gamma 1$ were required for association with LAT and all three $\mathrm{SH}$ domains were essential for enzyme activation. Furthermore, PLC- $\gamma 1$ activity depended on interactions with other LAT-associated proteins including SLP76 , the guanine nucleotide exchange factor Vav and the E3-ubiquitin ligase c-Cbl (Braiman et al. 2006).

Grb2 Family Members Bind Y171, Y191, and Y226 of Phosphorylated LAT and Recruit a Number of Signaling Proteins to the LAT Complex

The Grb2 family members Grb2, Gads, and Grap can potentially bind phosphorylated LAT at the distal three tyrosines: Y171, Y191, and Y226 (Wange 2000). Grb2 (Growth-factorreceptor-bound protein 2) is a ubiquitously expressed adapter protein that contains an $\mathrm{SH} 2$ domain flanked by amino- and carboxy-terminal SH3 domains. The Grb2 adapter is involved in Ras and MAP kinase pathway activation in many cell surface receptor systems, primarily by association with the guanine nucleotide exchange factor (GEF) Sos1. Interestingly, Grb2 association with LAT requires the $\mathrm{SH} 2$ domain of Grb2 and pairs of LAT phosphotyrosines: Y171/Y191, Y171/Y226, or Y191/Y226 (Zhang et al. 2000; Zhu et al. 2003). Gads (Grb2-related adapter protein downstream of Shc) contains a structure similar to Grb2, but also has a unique glutamine- and proline-rich domain between the $\mathrm{SH} 2$ domain and the carboxy-terminal SH3 domain. In addition to binding LAT, Gads binds SLP-76, which recruits a number of other signaling proteins including PLC- $\gamma 1$ (see Fig. 1B) (Liu et al. 1999; Zhang et al. 2000; Yablonski et al. 2001). Grap (Grb2-related adapter protein) is similar in structure to Grb2, but its role in T-cell signal transduction is not as well defined. It also associates with LAT through its SH2 domain (Trub et al. 1997; Zhang et al. 1998a). Studies of T cells from Grap-deficient mice indicate that Grap may be a negative regulator of TCR signal transduction (Shen et al. 2002).

Sos1 (Son of Sevenless homolog) is a multidomain GEF that promotes activation of the small $G$ protein Ras, which in turn activates the MAP kinase Erk (Quilliam 2007). Sos1 binds Grb2 constitutively (Wittekind et al. 1994; Houtman et al. 2006). Following TCR ligation, Grb2 recruits Sos1 to the site of Ras localization at the membrane. Early experiments suggested that a trimolecular complex formed between Grb2, Sos1, and LAT following TCR engagement (Buday et al. 1994; Sieh et al. 1994). Consistent with this, Zhang and colleagues reported that Sos1 did not associate with the LAT mutant Y171/191F, which also did not associate with Grb2 (Zhang et al. 1998a). Interestingly, the significance of a Grb2/Sos1 complex likely extends beyond the activation of Ras. Houtman and colleagues have described a mechanism whereby a 2:1 Grb2:Sos1 complex can facilitate clustering of LAT-based signaling complexes (to be discussed in more detail later) (Houtman et al. 2006).

The proto-oncogene $c$ - $\mathrm{Cbl}$ encodes a 120 $\mathrm{kDa}$ multidomain E3-ubiquitin ligase, which is phosphorylated and associates with LAT following TCR activation. c-Cbl also binds Grb2 constitutively (Donovan et al. 1994; Fukazawa et al. 1995b). Grb2 seems to be required for the interaction between c-Cbl and LAT, because c-Cbl does not associate with the LAT mutant Y171/191F, which fails to bind Grb2 (Zhang et al. 1998a). However, there is evidence that c-Cbl is also stabilized by interactions with other LAT-associated molecules, such as Nck (Rivero-Lezcano et al. 1994; Wunderlich et al. 1999), the p85 subunit of PI3K (Fukazawa et al. 1995b), and PLC- $\gamma 1$ (Rellahan et al. 2003; Chiang et al. 2004; Braiman et al. 2006). By stabilizing the associations of molecules that contribute to signal activation, $\mathrm{c}$-Cbl could promote positive TCR-induced signals; however, c-Cbl also appears to play a negative regulatory role in signaling.

In LAT-deficient Jurkat cells, c-Cbl is hyperphosphorylated upon TCR stimulation (Finco 
L. Balagopalan et al.

et al. 1998; Mingueneau et al. 2009) and phosphorylated c-Cbl has been implicated in negative regulation of TCR signal transduction (Boussiotis et al. 1997; Murphy et al. 1998). In addition, consistent with its role as an E3-ubiquitin ligase in several signaling systems, $\mathrm{c}-\mathrm{Cbl}$ has been implicated in ubiquitylation of the TCR $\zeta$ and CD3 $\delta$ chains of the TCR as well as the signaling proteins ZAP-70, LAT, PLC- $\gamma 1$, PI3K, Vav, and PKC- $\theta$ in T cells (Weissman 2001; Duan et al. 2004; Balagopalan et al. 2007). The effects of LAT ubiquitylation on controlling internalization and cellular LAT levels are discussed in the imaging section later.

\section{Molecules Recruited to LAT via SLP-76 Promote T-Cell Activation}

SLP-76 is an adapter protein containing three tyrosine motifs, a central proline-rich domain and a carboxy-terminal SH2 domain (Koretzky et al. 2006). The proline-rich domain of SLP-76 binds SH3 domains of Grb2 and Gads; however SLP-76 binds Gads with a 40-50-fold stronger affinity than Grb2 (Berry et al. 2002; Harkiolaki et al. 2003). Gads recruits SLP-76 to LAT by way of the interaction of its $\mathrm{SH} 2$ domain with phospho-LAT (Liu et al. 1999). SLP-76 recruits multiple effector molecules to the LAT complex. The three phosphotyrosines of SLP-76 bind PI3K, Vav, Itk, and Nck. The central prolinerich region binds to Gads with high affinity and to PLC- $\gamma 1$ with low affinity (Yablonski et al. 2001; Houtman et al. 2004). However, SLP-76 only associates weakly with LAT in the absence of the LAT residue Y132, suggesting that SLP-76 binding to LAT is stabilized by the presence of PLC- $\gamma 1$ (Zhang et al. 2000). The carboxy-terminal SH2 domain of SLP-76 interacts with the proteins HPK1, ADAP, and Shb. These interactions result in positive and negative effects on TCR signaling. Interactions that lead to negative effects on TCR signaling will be discussed in the following section.

PI3K is comprised of a $110 \mathrm{kDa}$ catalytic subunit and an $85 \mathrm{kDa}$ regulatory subunit ( $\mathrm{p} 85$ ) and catalyzes the phosphorylation of $\mathrm{PIP}_{2}$ to generate $\mathrm{PIP}_{3}$ (Fruman and Bismuth 2009). The accumulation of $\mathrm{PIP}_{3}$ facilitates membrane recruitment of proteins that contain $\mathrm{PH}$ domains, which recognize $\mathrm{PIP}_{3}$ (Fruman et al. 1999). In T cells, PI3K regulates the recruitment of proteins that facilitate TCR signal transduction such as PLC- $\gamma 1$, Sos1, RasGAP, Itk, Tec, and Vav. Early studies showed that PI3K bound directly to LAT (Fukazawa et al. 1995a; Lahesmaa et al. 1995; Paz et al. 2001); however more recent studies showed binding of $\mathrm{p} 85$ to tyrosine-phosphorylated SLP-76 (Shim et al. 2004). Inhibition of PI3K in T cells resulted in reduced TCR-induced calcium influx, Rac1 activation, and Erk1/2 phosphorylation. However, PI3K inhibition did not reduce the phosphorylation of $\mathrm{PH}$ domain-containing proteins such as PLC- $\gamma 1$ and Vav (Cruz-Orcutt and Houtman 2009). Therefore PI3K plays a role in TCR activation, but its exact mechanism is still unclear.

Other SLP-76 interactors have clearer roles on T-cell activation. Vav is a guanine nucleotide exchange factor that activates the Rho family G-proteins Rac1, RhoA, and Cdc42. A number of studies have demonstrated the importance of the association of the $\mathrm{Vav} \mathrm{SH} 2$ domain with SLP-76 phosphotyrosines (Koretzky et al. 2006). In addition to its catalytic role, Vav acts as a scaffold to stabilize PLC- $\gamma 1$ and Itk interactions with SLP-76. In Vav-deficient T cells, the interaction between SLP-76 and PLC- $\gamma 1$ was substantially reduced and Itk was not phosphorylated (Reynolds et al. 2002; Braiman et al. 2006). The Tec family kinase Itk phosphorylates PLC- $\gamma 1$ (Readinger et al. 2009) and LAT (Perez-Villar et al. 2002). Itk is recruited to the LAT complex by binding of its $\mathrm{SH} 2$ domain to tyrosine phosphorylated SLP-76 (Bunnell et al. 2000). Itk plays a major role in T-cell activation by virtue of its phosphorylation of PLC- $\gamma 1$, which is required for the activation of PLC- $\gamma 1$.

Vav and the adapters Nck and WASp cooperate to effect cytoskeletal changes in activated T cells. Nck binds phosphorylated SLP-76 (Wunderlich et al. 1999) and WASp (Wiskott-Aldrich syndrome protein) (Rohatgi et al. 2001; BardaSaad et al. 2005), bringing WASp in proximity to Vav. Vav recruits and activates Cdc42, which is necessary for WASp activation. Activated 
WASp interacts with the Arp2/3 complex to initiate actin polymerization and cytoskeletal changes (Zeng et al. 2003).

Two other adapter molecules that bind SLP76 and mediate positive signal transduction in $\mathrm{T}$ cells are ADAP and Shb. Phosphorylated ADAP binds the SH2 domain of SLP-76 (da Silva et al. 1997; Musci et al. 1997). This interaction is crucial for adhesion and integrin function in T cells (Baker et al. 2009; Horn et al. 2009; Wang et al. 2009). Tyrosine phosphorylated Shb also binds the SH2 domain of SLP-76 and promotes LAT, SLP-76, Vav, and PLC- $\gamma 1$ phosphorylation (Lindholm et al. 1999; Lindholm et al. 2002). HPK1 is another molecule that binds the SH2 domain of SLP-76 but mediates negative signal transduction.

\section{LAT Interactions also Inhibit TCR Signal Transduction}

Several molecules that bind to the LAT complex can inhibit TCR signal transduction. HPK1 (hematopoietic progenitor kinase 1) is a MAP4 kinase (Hu et al. 1996; Kiefer et al. 1996) that down-regulates activation of the MAP kinase Erk2 and the transcription factor AP-1 in a kinase-dependent manner (Liou et al. 2000). HPK-1 has a complex relationship with SLP76. It can phosphorylate SLP-76; however, this ultimately leads to decreased SLP-76 and PLC$\gamma 1$ phosphorylation and IL-2 production (Di Bartolo et al. 2007; Shui et al. 2007).

SHIP-1 is a lipid phosphatase that mediates $\mathrm{Fc}$ receptor-dependent negative signaling (Daeron and Lesourne 2006). In T cells, SHIP1 also acts as an adapter to recruit Dok-1 and Dok-2 to LAT complexes, which results in attenuated TCR signaling. SHIP-1-associated Dok1 and Dok-2 negatively regulate ZAP-70 activity (Dong et al. 2006; Yasuda et al. 2007) and recruit RasGAP, which opposes Ras-mediated signaling (Tamir et al. 2000; Ott et al. 2002). The adapter protein Gab2 also has several potential mechanisms for inhibiting signaling. It can bind SHP-2 (Yamasaki et al. 2001) and it may compete with SLP-76 for binding to Grb2 and Gads (Yamasaki et al. 2003). Other molecules that may mediate inhibitory signaling are the adapter SLAP (Src-like adapter protein) (Myers et al. 2006), the tyrosine phosphatase SHP-1 (Lorenz 2009) and 4.1R (Diakowski et al. 2006). 4.1R binds LAT directly and is thought to prevent LAT phosphorylation by ZAP-70 (Kang et al. 2009).

\section{COOPERATIVITY AMONG LAT-ASSOCIATED PROTEINS STABILIZES SIGNALING COMPLEXES}

It is clear that LAT plays a central role in T-cell activation downstream of the TCR by directly or indirectly recruiting kinases, effectors, and adapters to facilitate the coordination of highly regulated signal transduction pathways. Biophysical approaches have begun to reveal important insights into some of the molecular mechanisms that govern the stabilization of LAT-associated complexes. These studies indicate that numerous weak interactions cooperatively coordinate the formation of spatially and temporally specific signaling complexes.

\section{Qualitative Results Indicate Cooperativity Among LAT-Associated Proteins}

Cooperativity is an altered affinity between proteins because of interaction with other molecules and/or posttranslational modifications. A number of results suggest that LAT complexes are stabilized by cooperative interactions. $\mathrm{SH} 2$ domain-containing proteins including PLC$\gamma 1$, Grb2, and Gads bind directly to LAT phosphotyrosine motifs with a preference for PLC- $\gamma 1$ at pY132, Gads at pY191 and pY171, and Grb2 at pY171, pY191, and pY226 (Samelson 2002). Nevertheless, mutations of LAT Gads/Grb2-binding residues (Y171, Y191, and Y226) reduced PLC- $\gamma 1$ binding (Zhang et al. 2000; Hartgroves et al. 2003). At a minimum, Y132 and Y191 were required for an association between LAT and PLC- $\gamma 1$, indicating that PLC- $\gamma 1$ association with LAT was stabilized by Gads binding to LAT (Zhu et al. 2003). Likewise, there was evidence that PLC- $\gamma 1$ stabilized the binding of Grb2 to LAT. LAT Y132F mutation resulted in substantial losses of both Grb2 and PLC- $\gamma 1$ binding (Hartgroves et al. 2003). 
L. Balagopalan et al.

Experiments with LAT-nucleated signaling complexes on liposomes by Sangani and colleagues also indicated cooperativity. In these experiments Grb2 alone did not stably bind liposome-associated LAT; however, after incubation with Jurkat lysate, Grb2 associated along with Gads, PLC- $\gamma 1$, SLP-76, Itk, and Sos1 (Sangani et al. 2009). Interestingly, other studies showed that the LAT phosphorylation sites were required within a single molecule and could not be added in trans among multiple LAT proteins (Lin and Weiss 2001). This suggests that signaling complexes are stabilized around individual LAT molecules.

\section{LAT Binding Preferences are not Solely Driven by Affinities}

Binding studies were performed to better understand the basis for the specificity of the interactions of PLC- $\gamma 1$, Grb2, and Gads with individual LAT motifs. Interestingly, Grb2 and Gads did not have substantially different affinities for the pY171, pY191, or pY226 motifs, results that did not explain the preference of Gads for pY171 and pY191. However, the proteins had a 50-100-fold weaker affinity for pY132, which explained the lack of binding to that site. The PLC- $\gamma 1$ SH2 domain bound the pY132 motif with stronger affinity than the pY171, pY191, or pY226 motif; however, it was thought that the affinity difference alone would not account for its selectivity (Houtman et al. 2004). Overall, these studies indicated that the binding affinities alone were not sufficient to drive the apparent specificity of LAT motifs for PLC- $\gamma 1$ and Gads.

In addition to affinity, other factors likely contribute to the specificity of PLC- $\gamma 1$ for the LAT residue Y132. For example, the PLC- $\gamma 1$ PH domain would position PLC- $\gamma 1$ near the membrane, likely favoring interactions with pY132, as it is the most membrane proximal of the four motifs (Houtman et al. 2004). However, SLP-76 may also contribute to the stabilization of PLC- $\gamma 1$ binding to LAT. Binding studies had revealed a weak interaction between the SLP-76 proline-rich region and PLC$\gamma 1$; however, Houtman and colleagues showed that the interaction required structural changes within SLP-76. They showed that the high affinity interaction between Gads and SLP-76 stabilized the PLC- $\gamma 1$-binding conformation of SLP-76. Therefore, positive cooperativity mediated by the Gads/SLP-76 pair allowed PLC- $\gamma 1$ to bind SLP-76 (Houtman et al. 2004). Interestingly, LAT residue Y191 was phosphorylated substantially earlier than Y132 in $\mathrm{T}$ cells. Therefore, it is possible that the Gads/SLP-76 complex associates with LAT before PLC- $\gamma 1$. Moreover, SLP-76 is among the earliest proteins to be phosphorylated (Houtman et al. 2005). Phosphorylated SLP-76 binds Itk, which has been shown to phosphorylate the PLC- $\gamma 1$ residue Y783 (Bunnell et al. 2000; Serrano et al. 2005; Beach et al. 2007). Y783 of PLC- $\gamma 1$ is phosphorylated before LAT Y132, suggesting that PLC- $\gamma 1$ associates with the Gads/SLP-76/ Itk complex before binding to pY132 (Houtman et al. 2005). It was suggested that these cooperative binding events preceding PLC- $\gamma 1$ binding to LAT could allow for tight control of PLC- $\gamma 1$ activity.

\section{Cooperative Interactions Promote LAT Oligomerization}

Because LAT can potentially bind two or more Grb2 molecules and because the Grb2 SH3 ligands Sos1 and c-Cbl also contain multiple Grb2 binding sites, Houtman and colleagues investigated whether Grb2 complexes could link multiple LAT molecules into higher-order structures (Fig. 2). Biophysical studies were carried out to investigate the binding, composition and stiochiometry of complexes formed from mixtures of LAT with Grb2 and Sos1 or c-Cbl (Houtman et al. 2006; Houtman et al. 2007). The studies provided direct evidence that LAT was able to bind multiple Grb2 molecules and that the proline-rich regions of Sos 1 and c-Cbl each bound two Grb2 molecules. Interestingly, Grb2 bound the two regions of Sos 1 with either significantly different affinities or a twofold negative cooperativity in binding to the second site, whereby binding of the first Grb2 weakened the affinity of Sos 1 for a second Grb2 molecule. These results indicated that the 2:1 complex was 
Signaling through LAT

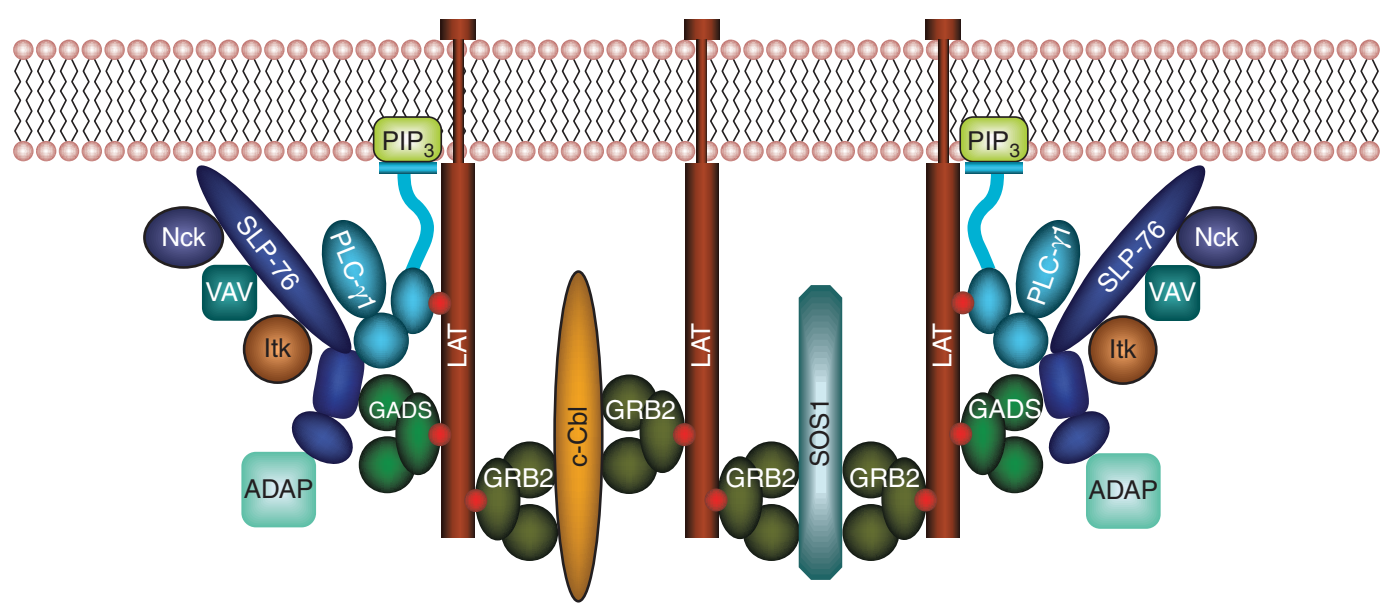

Figure 2. LAT complexes. Multiple LAT molecules are oligomerized by complexes of 2:1 Grb2:Sos1 or Grb2:Cbl in vitro and in cells. The clustering of LAT complexes is thought to be crucial for signal transduction and possibly for the control of TCR sensitivity to strong or weak stimuli.

only formed when Grb2 was in excess of Sos1. It was further demonstrated that Grb2 is in $\sim 1000$-fold excess of Sos 1 in T cells, suggesting that the 2:1 complex of Grb2 and Sos1, which forms in vitro could also be physiologically relevant in T cells (Houtman et al. 2006; Houtman et al. 2007). Next, it was shown that Grb2/Sos complexes could oligomerize LAT into large molecular complexes. Detailed studies of the energetics contributing to the complex formation showed that intermediate complexes, such as a 2:1 complex of Grb2:LAT, were slightly destabilized, consistent with negative cooperativity in their formation. In contrast, positive cooperative interactions resulted in a large stabilized molecular complex of LAT, Grb2, and Sos1. It was suggested that the presence of both negative and positive cooperativity in the formation of these complexes promoted the assembly of physiologically relevant complexes, while suppressing intermediates (Houtman et al. 2007). The relevance of Grb2-mediated LAT clustering was verified in vivo and was shown to have functional consequences on signaling and T-cell activation (Houtman et al. 2006).

The biophysical analyses of LAT and LATassociated proteins have revealed a role for intermolecular cooperativity in stabilizing LATnucleated complexes. Cooperativity allows for a high degree of organization of signaling molecules into macromolecular complexes visualized as "microclusters" using imaging techniques as described later.

\section{IMAGING OF LAT SIGNALING COMPLEXES AND CLUSTERS}

In the past decade, advanced microscopic approaches have provided striking images of the early events in T-cell activation. This section will review the contribution of imaging studies in developing a clearer understanding of the initiation, composition, dynamics, and spatiotemporal regulation of LAT-nucleated signaling complexes.

\section{LAT Microclusters: Sites of Nucleation of Signaling Complexes}

A little over a decade ago the immunological synapse (IS) was identified as a specialized junction between $\mathrm{T}$ cells and antigen presenting surfaces, which is characterized by a central cluster enriched for TCR-CD3 (cSMAC) and an integrin-rich peripheral cluster (pSMAC) (Monks et al. 1998). Subsequent studies identified the distal SMAC (dSMAC), an outer region that contains large molecules such as CD43 and CD45 (Delon et al. 2001; Freiberg et al. 2002). 
L. Balagopalan et al.

Real time visualization of the early events of T-cell activation has given greater temporal and spatial accuracy. Studies in which images were collected at the onset of T-cell activation showed that within the first $30 \mathrm{~s}$ of contact of a $\mathrm{T}$ cell with a stimulatory surface, small TCR-rich structures form at the periphery of the T-cell contact zone (Grakoui et al. 1999; Krummel et al. 2000). These discrete structures enriched for TCR have subsequently been called "microclusters."

The first high resolution images of LAT microclusters came from a method in which $\mathrm{T}$ cells were dropped onto stimulatory coverslips coated with $\mathrm{CD} 3$ antibody and visualized using confocal microscopy (Bunnell et al. 2002). Using this technique, LAT colocalized with TCR-rich microclusters within seconds of activation. In addition to LAT, a large number of components of the TCR signaling pathway including protein tyrosine kinases ZAP-70 and Lck, adapters SLP-76, Grb2, Gads, Nck and WASp, and enzymes including PLC- $\gamma 1$, Vav, $\mathrm{c}-\mathrm{Cbl}$, and Sos 1 were rapidly recruited to microclusters. Larger glycoproteins such as CD43 and the protein tyrosine phosphatase CD45 were excluded from these structures (Bunnell et al. 2002; Barda-Saad et al. 2005; Braiman et al. 2006; Houtman et al. 2006). These rapidly assembled clusters of signaling complexes were the predominant sites of TCR-induced tyrosine phosphorylation and their appearance was coincident with cytosolic $\mathrm{Ca}^{2+}$ elevations, establishing TCR microclusters as sites of signal initiation (Krummel et al. 2000; Bunnell et al. 2002; Seminario and Bunnell 2008). Thus microclusters are the smallest structures visible by confocal microscopy capable of driving effective TCR signaling and are made up of signaling complexes that contain adapters and effectors required for T-cell activation (Fig. 3).

Subsequent studies using peptide-MHCcontaining lipid bilayers and TIRF microscopy verified and extended these results (Campi et al. 2005; Yokosuka et al. 2005; Varma et al. 2006; Yokosuka et al. 2008; Kaizuka et al. 2009). Under these experimental conditions, microclusters were continuously generated at the periphery of the T-cell peptide-MHC interface and were transported and consolidated at the center of the contact to form a cSMAC (Varma et al. 2006). Microclusters play a predominant role in the generation of sustained signals. Current models also indicate that cluster centralization plays an important role in signal termination and that the cSMAC is a site both for TCR down-regulation yet also for amplification of weak signals (Lee et al. 2003; Mossman et al. 2005; Varma et al. 2006; Balagopalan et al. 2007; Cemerski et al. 2008; Nguyen et al. 2008). A recent study using a photoactivatable agonist in a lipid bilayer system has provided even greater precision in the temporal resolution of these events and demonstrated that adapters are recruited to microclusters within four seconds (Huse et al. 2007).

Fine spatial imaging studies indicated that signaling protein clusters may actually represent discrete interdigitating domains (Douglass and Vale 2005; Nguyen et al. 2008). These structures resembled the distinct protein and lipid domains observed by transmission electron microscopy (TEM) (Wilson et al. 2001; Lillemeier et al. 2006). TEM studies in mast cells and $\mathrm{T}$ cells have shown formation of "primary signaling domains" that include the receptor, and "secondary signaling domains" that include LAT and PLC- $\gamma 1$, but not the receptor. Apparently, these domains, submicron in size, preexist before receptor activation. Upon receptor activation, these domains were shown to concatenate to form larger patches that are likely equivalent to the microclusters observed by light microscopy (Wilson et al. 2001; Lillemeier et al. 2006; Lillemeier et al. 2009).

Because the resolution limit of the microscope $(\cong 200 \mathrm{~nm})$ is much larger than the size of individual proteins or protein complexes (on the order of a few nanometers), colocalization observed by fluorescence microscopy does not prove that proteins interact. Instead, Forster resonance energy transfer (FRET) can be employed to study colocalization on the scale of a few nanometers and therefore provides information about molecular interactions (Gascoigne et al. 2009). Using this technique, FRET was detected between PLC- $\gamma 1$ and either LAT, c-Cbl, Vav or SLP-76, as well as SLP-76 

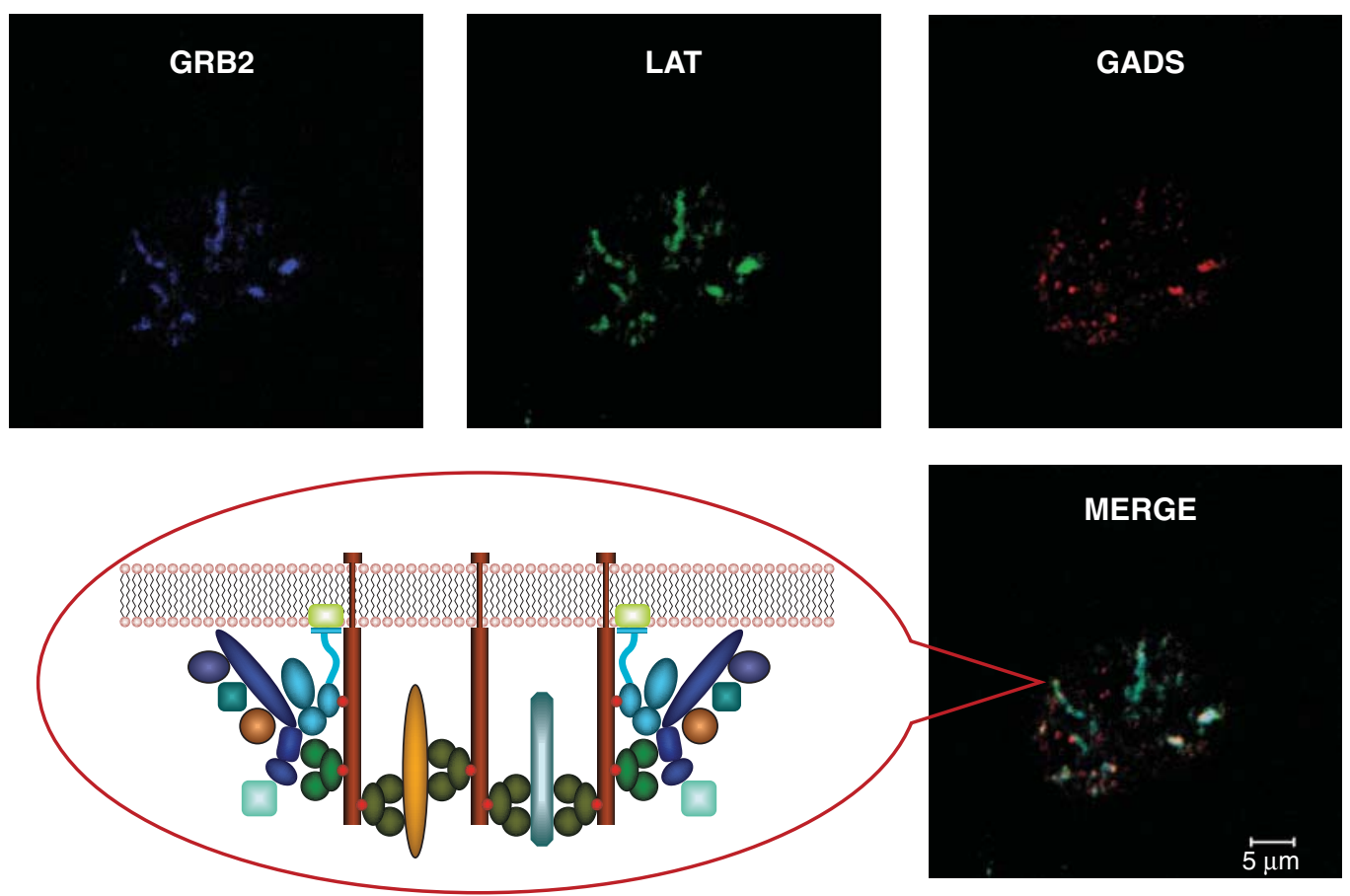

Figure 3. LAT signaling complexes and microclusters. A confocal image of the surface of a Jurkat E6.1 T cell dropped onto a TCR stimulatory coverslip shows LAT clusters, which colocalize with the LAT-binding proteins Grb2 and Gads. Grb2 (upper left) is in blue, LAT (upper middle) is in green and Gads (upper right) is in red. LAT signaling complexes (represented in the cartoon) form a pronounced network of heterogeneous and dynamic microclusters on the plasma membrane (see merge).

and Nck within microclusters, suggesting direct interactions of these proteins within microclusters (Barda-Saad et al. 2005; Braiman et al. 2006). In comparison, measurable but low FRET was observed between LAT and either SLP-76 or Nck, consistent with previous data showing that these molecules interact indirectly (Barda-Saad et al. 2005).

Another microscopic technique, fluorescence recovery after photobleaching (FRAP), has been used to evaluate LAT dynamics at the population level. This method allows evaluation of mobility and population-level diffusion dynamics of molecules (Tanimura et al. 2003a). Studies on LAT dynamics at the membrane revealed the fast exchange of molecules between LAT clusters or patches localized at sites of stimulation (Tanimura et al. 2003b; Douglass and Vale 2005). Single-molecule imaging studies have revealed that LAT molecules at the plasma membrane display abrupt changes between immobility and rapid diffusion (Douglass and Vale 2005). Transient immobilization of LAT correlated strongly with encounter with clusters. These data indicate that LAT molecules diffuse between clusters with occasional trapping within clusters.

\section{Mechanisms of Assembly of LAT Clusters and LAT-Nucleated Complexes}

Data from various experimental systems have shown that microclusters play a crucial role in TCR-mediated signaling pathways because inhibition of cluster formation resulted in reduced levels of TCR signaling (Singer et al. 2004; Bunnell et al. 2006; Houtman et al. 2006). The importance of clustering may be to concentrate activators and exclude inhibitors creating microdomains that shift the equilibrium to favor downstream signaling in $\mathrm{T}$ cells. However, the mechanisms that govern the 
L. Balagopalan et al.

assembly of these structures have remained elusive. Because LAT is both a lipid raft resident and an adapter with multiple tyrosines that serve as docking sites for signaling proteins, the contribution of both lipid rafts as well as protein scaffolds in LAT clustering has been investigated.

Early studies indicated that lipid raft patches form at the sites of TCR activation and copatched with proteins essential for T-cell activation (Harder and Simons 1999; Janes et al. 1999). Hence it was proposed that lipid rafts provide a platform for assembly of signaling domains during T-cell activation. However, data from multiple studies indicated that membrane recruitment, not raft localization was required for LAT function (Zhu et al. 2005; Hundt et al. 2009). Furthermore, Harder and Kuhn showed that LAT, but not other raft-associated molecules such as Lck and GM1, was selectively enriched within plasma membrane fragments containing activated TCR, calling into question the view that upon TCR activation coalescence of raft-associated membrane proteins in the vicinity of activated TCR leads to T-cell triggering (Harder and Kuhn 2000). Imaging studies also showed that LAT did not colocalize with a general raft marker GFP-GPI (Bunnell et al. 2002). Together, these studies indicate that lipid rafts are not a primary factor in the assembly of LAT-containing signaling complexes.

Instead, several studies have indicated that phosphotyrosine-dependent protein interactions play the predominant role in organization of TCR-dependent signaling complexes. First, LAT was not recruited to TCR-enriched immunoisolates in cells treated with the potent Src kinase inhibitor PP2 (Harder and Kuhn 2000). Second, imaging approaches using planar substrates demonstrated that LAT variants with mutated tyrosines in the cytoplasmic tail were not recruited to signaling microclusters (Douglass and Vale 2005; Bunnell et al. 2006; Houtman et al. 2006). Finally, single particle tracking techniques as well as FRAP methods that measured diffusion rates of LAT revealed that LAT cytoplasmic tyrosines are required for confinement of LAT within transient subdomains (Tanimura et al. 2003b; Douglass and Vale 2005). In contrast, interfering with lipid raft association of LAT through mutations did not alter its diffusion behavior (Douglass and Vale 2005).

The earlier-described results are most consistent with LAT clusters being formed and maintained by a network of protein-protein interactions. The combination of biochemical and biophysical studies has shown that cooperative and multivalent interactions drive the assembly of productive signaling complexes and imaging approaches have supported this scenario. Houtman et al. used confocal microscopy to verify the physiological relevance of Grb2-Sos1-mediated oligomerization of LAT, observed by biophysical techniques (Houtman et al. 2006). A LAT mutant unable to bind Grb2 did not localize to signaling clusters. In addition, expression of a Sos1 fragment unable to oligomerize LAT inhibited LAT clustering and downstream signaling. Thus, multivalent interactions between these three molecules appeared to promote the assembly of multiprotein complexes important for TCR activation. In another study using confocal approaches, Bunnell and colleagues demonstrated that cooperative interactions between LAT, Gads and SLP-76 stabilized SLP-76 microclusters (Bunnell et al. 2006). Another report demonstrated that although the SH3 and C-terminal SH2 domains of PLC- $\gamma 1$ do not bind directly to LAT, they participate in the stabilization of PLC- $\gamma 1$-LATassociation via other proteins in the LAT-nucleated signaling complex (Braiman et al. 2006).

Finally, several studies have argued that actin is required for segregating molecules on the T-cell surface (Wulfing and Davis 1998; Delon et al. 2001). F actin was present at microclusters and the contact sites of T cells and stimulatory surfaces at early time points (Bunnell et al. 2001; Barda-Saad et al. 2005). TEM studies of Wilson et al. in mast cells also support the interaction of the actin cytoskeleton with receptor clusters (Wilson et al. 2001). Furthermore, inhibitor studies showed that actin is essential for the formation of microclusters (Campi et al. 2005; Douglass and Vale 2005; Varma et al. 2006; Nguyen et al. 2008). An intact cytoskeleton is also required for dynamic translocation of clusters once they are formed and it 
has been proposed that retrograde actin flow drives centripetal cluster movement (Barr et al. 2006; Varma et al. 2006; Kaizuka et al. 2007; Nguyen et al. 2008; Ilani et al. 2009). In this regard, microclusters must be connected to actin filaments via linker proteins, and LAT-mediated recruitment of actin-regulating adapters Nck and WASp to these structures may play a central role in this process (Barda-Saad et al. 2005).

\section{Dynamics of LAT Clusters, LAT Internalization and LAT Ubiquitylation}

The dynamic nature and changing composition of TCR microclusters after they are generated has been extensively demonstrated. Across all modeling systems, following initial recruitment in close proximity of the TCR, components of the complexes rapidly exit microclusters with distinct dynamics (Bunnell et al. 2002; BardaSaad et al. 2005; Braiman et al. 2006). The adapters LAT and SLP-76 departed the initial complexes in what appeared to be small vesicular intermediates and dissipated soon thereafter (Bunnell et al. 2002). Recent studies have shown that microclusters containing LAT and SLP-76 undergo endocytosis upon TCR stimulation (Barr et al. 2006; Balagopalan et al. 2007). SLP-76 is endocytosed in a lipid-raft dependent pathway that requires the association of the endocytic machinery with ubiquitylated proteins. LAT endocytosis is a complex process and internalized LAT is found in several intracellular compartments (Bonello et al. 2004; Brignatz et al. 2005; Balagopalan et al. 2007). Insights into the molecular mechanisms that regulate endocytosis of microcluster-associated proteins came from studies in which internalization of the microclusters was inhibited. First, expression of versions of $\mathrm{c}-\mathrm{Cbl}$ that are defective in the RING domain that mediates ubiquitin ligase activity severely inhibited LAT and SLP76 movement and endocytosis. Furthermore, the ubiquitin-interacting motif(UIM) of eps15, which is known to block clathrin-independent internalization of the EGFR (Sigismund et al. 2005), severely inhibited the internalization of SLP-76 clusters (Barr et al. 2006). Thus, the $\mathrm{E} 3$ ligase $\mathrm{c}-\mathrm{Cbl}$ and ubiquitin appear to be intimately involved in the sorting of LAT and SLP-76 into mobile endocytic structures.

In addition to containing tyrosines, the LAT cytoplasmic domain contains two lysines that could serve as sites of ubiquitylation. Indeed LAT ubiquitylation has been observed both in Jurkat $\mathrm{T}$ cells and in COS-7 cells (Brignatz et al. 2005; Balagopalan et al. 2007). Consistent with c-Cbl being an E3 ligase for LAT ubiquitylation, expression of c-Cbl caused a modest increase in LAT ubiquitylation. In contrast, the RING finger mutant caused a significant decrease in ubiquitylated LAT species. These data are consistent with a model in which c-Cblmediated ubiquitylation is required for rapid internalization of LAT-nucleated signaling clusters. Given the essential scaffolding role of the adapter protein LAT in $\mathrm{T}$ cell activation, the regulated internalization of activated LAT signaling complexes may be one efficient strategy by which to control the duration and localization of signaling from microclusters and, thus, regulate the kinetics, intensity, and specificity of T-cell signaling. For a detailed discussion on endocytic regulation of T-cell microclusters, see Balagopalan et al. 2009.

\section{ANIMAL STUDIES REVEAL THE IN VIVO FUNCTIONS OF LAT}

Although T-cell lines have been enormously useful for discerning the role of LAT in T-cell function within single T cells, animal model systems provide the opportunity to study the function of LAT during T-cell development as well as its function in T cells in the context of the entire immune system.

\section{Studies of LAT Null Mice}

Studies of LAT null mice show the crucial importance of LAT in pre-TCR and TCR signaling. $\alpha \beta$ T-cell development proceeds through ordered stages that can be characterized by expression of the cell surface markers CD4 and CD8: DN (double negative for CD4 and $\mathrm{CD} 8) \rightarrow \mathrm{DP}$ (double positive for CD4 and $\mathrm{CD} 8) \rightarrow \mathrm{SP}$ (single positive for either CD4 or CD8). The DN stage can further be divided 
L. Balagopalan et al.

into four stages based on the expression of the cell surface markers CD44 and CD25: DN1 $\left(\mathrm{CD} 44^{+} \mathrm{CD} 25^{-}\right) \rightarrow \mathrm{DN} 2 \quad\left(\mathrm{CD} 44^{+} \mathrm{CD} 25^{+}\right) \rightarrow$ $\mathrm{DN} 3\left(\mathrm{CD} 44^{-} \mathrm{CD} 25^{+}\right) \rightarrow \mathrm{DN} 4\left(\mathrm{CD} 44^{-} \mathrm{CD} 25^{-}\right)$. Signaling through the immature, nonclonotypic pre-TCR drives development from the DN3 to the DN4 stage. Mature TCR signaling drives T-cell development from the DP to SP stage. During the $\mathrm{DP} \rightarrow \mathrm{SP}$ transition, thymocytes are tested based on their TCR specificities and are selected for survival (by positive selection, based on MHC specificity and nonself reactivity) or death (by negative selection, based on potential self-reactivity) (Sommers et al. 2004).

In LAT knockout mice, the endogenous wild-type LAT gene was replaced with a mutant form of the gene that could not be expressed by homologous recombination (Zhang et al. 1999b). LAT knockout mice showed a complete block in $\alpha \beta$ T-cell development at the immature, DN3 stage indicating an essential role for LAT in pre-TCR signaling. No peripheral $\alpha \beta$ T cells were observed. To investigate the role of LAT in mature TCR signaling, Shen et al. used a conditional knockout approach (Shen et al. 2009). Their approach used Cre-Lox technology (Wang 2009), whereby conditional expression of the Cre recombinase allowed deletion of a LoxP-flanked sequence that resulted in T cellspecific disruption of expression of LAT at the DP stage. The authors observed a severe block in the $\mathrm{DP} \rightarrow \mathrm{SP}$ stage of thymocyte development indicating a strong role for LAT in TCR-mediated thymocyte selection. However, some CD4 and CD8 SP T cells developed in these mice and it was unclear whether these $\mathrm{T}$ cells developed because of residual LAT in some developing DPs or because LAT is not completely essential for the DP $\rightarrow$ SP transition (Shen et al. 2009).

In Vivo Functions of LAT Phosphotyrosines and Cysteines

Previous in vitro studies with C26/29A LAT mutants had shown that the mutant LAT molecules could not be tyrosine phosphorylated, did not localize to plasma membrane rafts and could not mediate TCR signaling (Zhang et al. 1998b). In the animal experiments, LAT knockout bone marrow cells were infected with retroviruses containing mutant LAT C26/29A. The infected bone marrow cells were transferred to irradiated wild type B6 mice and the mutant LAT was unable to mediate T-cell development (Hundt et al. 2009). To assess whether raft localization (in addition to plasma membrane localization) was necessary for the in vivo function of LAT, several approaches have been taken using LAT fusion proteins. LATLAX and Src-LAT fusion proteins localized to the plasma membrane but not to rafts. Both of these fusion proteins mediated T-cell development in LAT-deficient environments (Zhu et al. 2005; Hundt et al. 2009). Therefore C26 and C29 of LAT were necessary for plasma membrane localization and for the in vivo function of LAT, but raft localization was not necessary for T-cell development.

In vitro experiments have shown the importance of the distal four phosphotyrosines for the function of LAT. A "knock-in" LAT mutant in which the endogenous wild type LAT gene was replaced with a mutant form of LAT containing $\mathrm{Y} \rightarrow \mathrm{F}$ substitutions at the four distal tyrosines revealed that those four distal tyrosines were required for T-cell development (Sommers et al. 2001). Knock-in mutants of $\mathrm{Y} 136 \rightarrow \mathrm{F}$ (corresponding to human $\mathrm{Y} 132 \rightarrow \mathrm{F}$ ) showed an incomplete block in early $\alpha \beta$ T cell development and a fatal lymphoproliferative disease involving marked lymphadenopathy, splenomegaly, and multiorgan lymphocyte infiltration (Fig. 4) (Aguado et al. 2002; Sommers et al. 2002). A knock-in LAT mutant containing $Y \rightarrow F$ mutations at Y175, Y195, and Y235, (corresponding to human Y171, Y191, and Y226) also developed lymphoproliferative disease (Nunez-Cruz et al. 2003). Although the lymphoproliferative phenotypes of these two mouse models were similar, the intrathymic T-cell development differed between these two models. In LAT Y136F knock-in mice, some $\alpha \beta \mathrm{T}$ cells developed and expanded, whereas in LAT Y175/195/235F knock-in mice, cells of the $\gamma \delta$ $\mathrm{T}$ cells lineage developed and expanded.

In addition to the developmental block in LAT Y136F mice, thymocyte selection was profoundly affected (Sommers et al. 2005) and Treg 

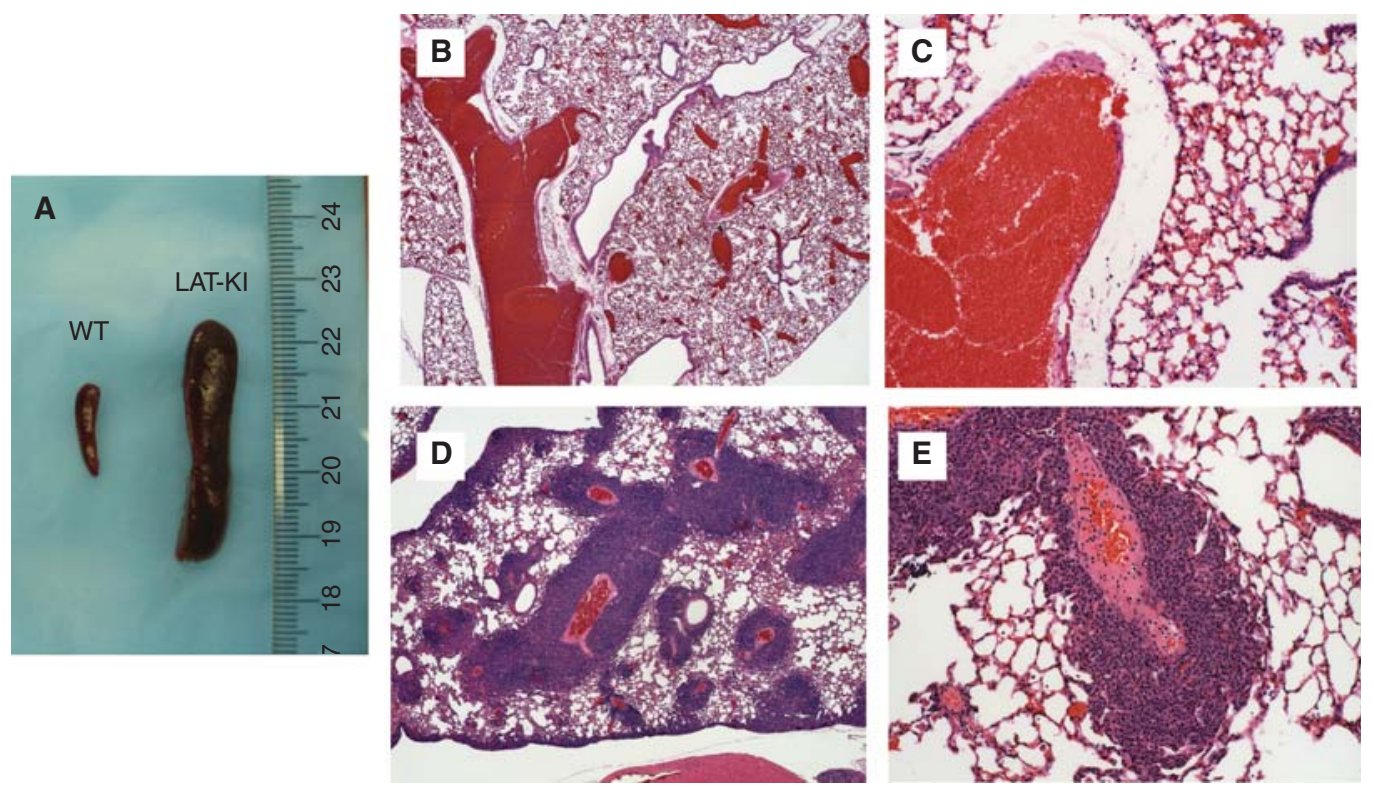

Figure 4. Lymphoproliferative disease in LAT Y136F KI mice. (A) Spleens from 10-week-old wild type C57BL/6 and LAT Y136F KI mice are shown. The ruler depicts centimeters. $(B-E)$ Lymphocyte infiltration into lung. $\mathrm{H} \& \mathrm{E}$-stained sections of lung from wild type C57BL/6 $(B, C)$ and LAT Y136F KI mice $(D, E)$ are shown. Images were photographed using a $2 \mathrm{X}(B, D)$ or $10 \mathrm{X}(C, E)$ objective.

cells (Lu and Rudensky 2009) did not develop (Koonpaew et al. 2006; Wang et al. 2008). Abnormal cytokine production was observed in these mice, especially elevated levels of IL-4. In fact the mice showed many aspects of Th2 lymphoproliferative disease including $\operatorname{IgG1}$ and IgE hypergammaglobulinemia, elevated serum IL-4, eosinophilia, and lymphocyte proliferation in lungs (Aguado et al. 2002; Sommers et al. 2002; Genton et al. 2006; Miyaji et al. 2009). The contributing factors leading to development of lymphoproliferative disease are still under investigation, but some are known. Altered or crippled signaling leads to a block in T-cell development and a lymphopenic environment. Altered signaling in the T cells developing in this lymphopenic environment results in T-cell hyperproliferation, defective activation-induced cell death and altered cytokine production ( $\uparrow$ IL-4, $\downarrow$ IL-2). Lack of development and function of Treg cells may be secondary to decreased IL-2 production. Altered signaling in LAT Y136F T cells consists of decreased TCR-induced calcium flux and other events downstream of PLC- $\gamma 1$ (Sommers et al. 2002). Reports of Erk $1 / 2$ activation in LAT Y136F T cells have been variable (Sommers et al. 2002; Mingueneau et al. 2009; Miyaji et al. 2009), most likely because of different methods of in vitro activation and age of the animals from which the $\mathrm{T}$ cells were derived. However, a report by Miyaji et al. showed that Erk activation played an important role in lymphoproliferative disease in LAT Y136F mice (Miyaji et al. 2009). Precisely how other aspects of altered signaling (especially altered calcium signaling) lead to hyperproliferation, decreased cell death and altered cytokine production in LAT Y136FT cells is a subject for future investigations.

\section{LAT-Independent TCR Signaling}

A recent report by Mingueneau et al. highlights a mouse model in which LAT-independent $\mathrm{T}$ cell signaling was demonstrated (Mingueneau et al. 2009). In these experiments, $\mathrm{CD} 4^{+} \mathrm{T}$ cells that had developed in a LAT-sufficient environment were rendered LAT-deficient following 
L. Balagopalan et al.

expression of Cre recombinase, which was accomplished by retroviral infection. After additional culturing with IL-2, the cells were stimulated through the TCR and various responses were assessed or the $\mathrm{T}$ cells were adoptively transferred to $\mathrm{T}$ cell-deficient hosts. Although phosphorylation of several key signaling molecules was not observed in the LAT-deficient mature T cells (including PLC- $\gamma 1$ and Erk $1 / 2$ ), phosphorylation of some signaling molecules was observed (e.g., SLP-76 and Akt). TCR-induced calcium flux and interferon- $\gamma$ production were also profoundly diminished in these cells. However, these experiments lend credence to the hypothesis that although LAT is critical for TCR signaling, some TCRinduced, LAT-independent signaling can occur in mature T cells. Furthermore, LAT-deficient mature $\mathrm{T}$ cells that had developed in a LATsufficient environment could initiate lymphoproliferative disease when transferred into T-cell-deficient (CD3e knockout) hosts. This raises the fascinating possibility that TCRinduced, LAT-independent signaling mechanisms (in a lymphopenic context) can lead to lymphoproliferative disease. It will be interesting to compare the LAT-independent signaling mechanisms from this situation with LAT-independent signaling described in T-cell clones (Chau and Madrenas 1999) and in Jurkat T cells (Ku et al. 2001; Shan et al. 2001).

\section{CONCLUDING REMARKS}

As described in this review, identification of the critical adapter molecule LAT over a decade ago has led to a multitude of studies. Our understanding of TCR-mediated signaling and T cell biology in general has been thereby enriched. We expect that continued application of stateof-the-art approaches will lead to further insight into how LAT serves as the focal point of TCR-mediated activation.

\section{ACKNOWLEDGMENTS}

The authors would like to thank Robert Kortum, Valarie Barr and Ronald Wange for helpful suggestions.

\section{REFERENCES}

Aguado E, Richelme S, Nunez-Cruz S, Miazek A, Mura AM, Richelme M, Guo XJ, Sainty D, He HT, Malissen B, et al. 2002. Induction of $\mathrm{T}$ helper type 2 immunity by a point mutation in the LAT adaptor. Science 296: 2036-2040.

Baker RG, Hsu CJ, Lee D, Jordan MS, Maltzman JS, Hammer DA, Baumgart T, Koretzky GA. 2009. The adapter protein SLP-76 mediates "outside-in" integrin signaling and function in T cells. Mol Cell Biol 29: 5578-5589.

Baker JE, Majeti R, Tangye SG, Weiss A. 2001. Protein tyrosine phosphatase CD148-mediated inhibition of T-cell receptor signal transduction is associated with reduced LAT and phospholipase C $\gamma 1$ phosphorylation. Mol Cell Biol 21: 2393-2403.

Balagopalan L, Barr VA, Samelson LE. 2009. Endocytic events in TCR signaling: Focus on adapters in microclusters. Immunol Rev 232: 84-98.

Balagopalan L, Barr VA, Sommers CL, Barda-Saad M, Goyal A, Isakowitz MS, Samelson LE. 2007. c-Cbl-mediated regulation of LAT-nucleated signaling complexes. $\mathrm{Mol}$ Cell Biol 27: 8622-8636.

Barda-Saad M, Braiman A, Titerence R, Bunnell SC, Barr VA, Samelson LE. 2005. Dynamic molecular interactions linking the $\mathrm{T}$ cell antigen receptor to the actin cytoskeleton. Nat Immunol 6: 80-89.

Barr VA, Balagopalan L, Barda-Saad M, Polishchuk R, Boukari H, Bunnell SC, Bernot KM, Toda Y, Nossal R, Samelson LE. 2006. T-cell antigen receptor-induced signaling complexes: Internalization via a cholesteroldependent endocytic pathway. Traffic 7: 1143-1162.

Beach D, Gonen R, Bogin Y, Reischl IG, Yablonski D. 2007. Dual role of SLP-76 in mediating T cell receptor-induced activation of phospholipase C- $\gamma 1$. J Biol Chem 282: 2937-2946.

Berry DM, Nash P, Liu SK, Pawson T, McGlade CJ. 2002. A high-affinity Arg-X-X-Lys SH3 binding motif confers specificity for the interaction between Gads and SLP-76 in T cell signaling. Curr Biol 12: 1336-1341.

Bonello G, Blanchard N, Montoya MC, Aguado E, Langlet C, He HT, Nunez-Cruz S, Malissen M, Sanchez-Madrid F, Olive D, et al. 2004. Dynamic recruitment of the adaptor protein LAT: LAT exists in two distinct intracellular pools and controls its own recruitment. J Cell Sci 117: 1009-1016.

Boussiotis VA, Freeman GJ, Berezovskaya A, Barber DL, Nadler LM. 1997. Maintenance of human T cell anergy: Blocking of IL-2 gene transcription by activated Rap1. Science 278: 124-128.

Braiman A, Barda-Saad M, Sommers CL, Samelson LE. 2006. Recruitment and activation of PLC $\gamma 1$ in T cells A new insight into old domains. EMBO J 25: 774-784.

Brdicka T, Cerny J, Horejsi V. 1998. T cell receptor signalling results in rapid tyrosine phosphorylation of the linker protein LAT present in detergent-resistant membrane microdomains. Biochem Biophys Res Commun 248: 356-360.

Brignatz C, Restouin A, Bonello G, Olive D, Collette Y. 2005 Evidences for ubiquitination and intracellular trafficking of LAT, the linker of activated T cells. Biochim Biophys Acta 1746: 108-115. 
Brown DA. 2006. Lipid rafts, detergent-resistant membranes, and raft targeting signals. Physiology (Bethesda) 21: 430439.

Brown DA, London E. 1998. Structure and origin of ordered lipid domains in biological membranes. J Membr Biol 164: 103-114

Buday L, Egan SE, Rodriguez Viciana P, Cantrell DA, Downward J. 1994. A complex of Grb2 adaptor protein, Sos exchange factor, and a $36-\mathrm{kDa}$ membrane-bound tyrosine phosphoprotein is implicated in ras activation in T cells. J Biol Chem 269: 9019-9023.

Bunnell SC, Diehn M, Yaffe MB, Findell PR, Cantley LC, Berg LJ. 2000. Biochemical interactions integrating Itk with the $\mathrm{T}$ cell receptor-initiated signaling cascade. I Biol Chem 275: 2219-2230.

Bunnell SC, Hong DI, Kardon JR, Yamazaki T, McGlade CJ, Barr VA, Samelson LE. 2002. T cell receptor ligation induces the formation of dynamically regulated signaling assemblies. J Cell Biol 158: 1263-1275.

Bunnell SC, Kapoor V, Trible RP, Zhang W, Samelson LE 2001. Dynamic actin polymerization drives T cell receptor-induced spreading: A role for the signal transduction adaptor LAT. Immunity 14: 315-329.

Bunnell SC, Singer AL, Hong DI, Jacque BH, Jordan MS, Seminario MC, Barr VA, Koretzky GA, Samelson LE 2006. Persistence of cooperatively stabilized signaling clusters drives T-cell activation. Mol Cell Biol 26: 7155-7166.

Campi G, Varma R, Dustin ML. 2005. Actin and agonist MHC-peptide complex-dependent $\mathrm{T}$ cell receptor microclusters as scaffolds for signaling. J Exp Med 202: 1031-1036.

Cemerski S, Das J, Giurisato E, Markiewicz MA, Allen PM, Chakraborty AK, Shaw AS. 2008. The balance between T cell receptor signaling and degradation at the center of the immunological synapse is determined by antigen quality. Immunity 29: 414-422.

Chau LA, Madrenas J. 1999. Phospho-LAT-independent activation of the ras-mitogen-activated protein kinase pathway: A differential recruitment model of TCR partial agonist signaling. J Immunol 163: 1853-1858.

Chiang YJ, Sommers CL, Jordan MS, Gu H, Samelson LE, Koretzky GA, Hodes RJ. 2004. Inactivation of c-Cbl reverses neonatal lethality and $\mathrm{T}$ cell developmental arrest of SLP-76-deficient mice. J Exp Med 200: 25-34.

Cruz-Orcutt N, Houtman JC. 2009. PI3 kinase function is vital for the function but not formation of LAT-mediated signaling complexes. Mol Immunol 46: 2274-2283.

da Silva AJ, Li Z, de Vera C, Canto E, Findell P, Rudd CE. 1997. Cloning of a novel T-cell protein FYB that binds FYN and SH2-domain-containing leukocyte protein 76 and modulates interleukin 2 production. Proc Natl Acad Sci 94: 7493-7498.

Daeron M, Lesourne R. 2006. Negative signaling in Fc receptor complexes. Adv Immunol 89: 39-86.

Delon J, Kaibuchi K, Germain RN. 2001. Exclusion of CD43 from the immunological synapse is mediated by phosphorylation-regulated relocation of the cytoskeletal adaptor moesin. Immunity 15: 691-701.

Di Bartolo V, Montagne B, Salek M, Jungwirth B, Carrette F, Fourtane J, Sol-Foulon N, Michel F, Schwartz O,
Lehmann WD, et al. 2007. A novel pathway down-modulating $\mathrm{T}$ cell activation involves HPK-1-dependent recruitment of 14-3-3 proteins on SLP-76. J Exp Med 204: 681-691.

Diakowski W, Grzybek M, Sikorski AF. 2006. Protein 4.1, a component of the erythrocyte membrane skeleton and its related homologue proteins forming the protein 4.1/FERM superfamily. Folia Histochem Cytobiol 44: 231-248.

Dong S, Corre B, Foulon E, Dufour E, Veillette A, Acuto O, Michel F. 2006. T cell receptor for antigen induces linker for activation of $\mathrm{T}$ cell-dependent activation of a negative signaling complex involving Dok-2, SHIP-1, and Grb-2. J Exp Med 203: 2509-2518.

Donovan JA, Wange RL, Langdon WY, Samelson LE. 1994. The protein product of the c-cbl protooncogene is the $120-\mathrm{kDa}$ tyrosine-phosphorylated protein in Jurkat cells activated via the T cell antigen receptor. J Biol Chem 269: 22921-22924.

Douglass AD, Vale RD. 2005. Single-molecule microscopy reveals plasma membrane microdomains created by protein-protein networks that exclude or trap signaling molecules in T cells. Cell 121: 937-950.

Duan L, Reddi AL, Ghosh A, Dimri M, Band H. 2004. The $\mathrm{Cbl}$ family and other ubiquitin ligases: Destructive forces in control of antigen receptor signaling. Immunity 21: $7-17$.

Facchetti F, Chan JK, Zhang W, Tironi A, Chilosi M, Parolini S, Notarangelo LD, Samelson LE. 1999. Linker for activation of T cells (LAT), a novel immunohistochemical marker for T cells, NK cells, mast cells, and megakaryocytes: Evaluation in normal and pathological conditions. Am J Pathol 154: 1037-1046.

Finco TS, Kadlecek T, Zhang W, Samelson LE, Weiss A. 1998. LAT is required for TCR-mediated activation of PLC $\gamma 1$ and the Ras pathway. Immunity 9: 617-626.

Freiberg BA, Kupfer H, Maslanik W, Delli J, Kappler J, Zaller DM, Kupfer A. 2002. Staging and resetting T cell activation in SMACs. Nat Immunol 3: 911-917.

Fruman DA, Bismuth G. 2009. Fine tuning the immune response with PI3K. Immunol Rev 228: 253-272.

Fruman DA, Rameh LE, Cantley LC. 1999. Phosphoinositide binding domains: Embracing 3-phosphate. Cell 97: 817-820.

Fukazawa T, Reedquist KA, Panchamoorthy G, Soltoff S, Trub T, Druker B, Cantley L, Shoelson SE, Band H. 1995a. T cell activation-dependent association between the p85 subunit of the phosphatidylinositol 3-kinase and Grb2/phospholipase C- $\gamma$ 1-binding phosphotyrosyl protein pp36/38. J Biol Chem 270: 20177-20182.

Fukazawa T, Reedquist KA, Trub T, Soltoff S, Panchamoorthy G, Druker B, Cantley L, Shoelson SE, Band H. 1995b. The SH3 domain-binding T cell tyrosyl phosphoprotein $\mathrm{p} 120$. Demonstration of its identity with the $\mathrm{c}-\mathrm{cbl}$ protooncogene product and in vivo complexes with Fyn, Grb2, and phosphatidylinositol 3-kinase. J Biol Chem 270: $19141-19150$.

Gascoigne NR, Ampudia J, Clamme JP, Fu G, Lotz C, Mallaun M, Niederberger N, Palmer E, Rybakin V, Yachi $\mathrm{PP}$, et al. 2009. Visualizing intermolecular interactions in T cells. Curr Top Microbiol Immunol 334: 31-46. 
L. Balagopalan et al.

Genton C, Wang Y, Izui S, Malissen B, Delsol G, Fournie GJ, Malissen M, Acha-Orbea H. 2006. The Th2 lymphoproliferation developing in LatY136F mutant mice triggers polyclonal B cell activation and systemic autoimmunity. J Immunol 177: 2285-2293.

Gilliland LK, Schieven GL, Norris NA, Kanner SB, Aruffo A, Ledbetter JA. 1992. Lymphocyte lineage-restricted tyrosine-phosphorylated proteins that bind PLC $\gamma 1$ SH2 domains. J Biol Chem 267: 13610-13616.

Grakoui A, Bromley SK, Sumen C, Davis MM, Shaw AS, Allen PM, Dustin ML. 1999. The immunological synapse: A molecular machine controlling T cell activation. Science 285: 221-227.

Gringhuis SI, Leow A, Papendrecht-Van Der Voort EA, Remans PH, Breedveld FC, Verweij CL. 2000. Displacement of linker for activation of $\mathrm{T}$ cells from the plasma membrane due to redox balance alterations results in hyporesponsiveness of synovial fluid T lymphocytes in rheumatoid arthritis. J Immunol 164: 2170-2179.

Harder T, Kuhn M. 2000. Selective accumulation of raft-associated membrane protein LAT in T cell receptor signaling assemblies. J Cell Biol 151: 199-208.

Harder T, Simons K. 1999. Clusters of glycolipid and glycosylphosphatidylinositol-anchored proteins in lymphoid cells: Accumulation of actin regulated by local tyrosine phosphorylation. Eur J Immunol 29: 556-562.

Harkiolaki M, Lewitzky M, Gilbert RJ, Jones EY, Bourette RP, Mouchiroud G, Sondermann H, Moarefi I, Feller SM. 2003. Structural basis for SH3 domain-mediated high-affinity binding between Mona/Gads and SLP-76. EMBO J 22: 2571-2582.

Hartgroves LC, Lin J, Langen H, Zech T, Weiss A, Harder T. 2003. Synergistic assembly of linker for activation of $\mathrm{T}$ cells signaling protein complexes in T cell plasma membrane domains. J Biol Chem 278: 20389-20394.

He HT, Marguet D. 2008. T-cell antigen receptor triggering and lipid rafts: A matter of space and time scales. Talking Point on the involvement of lipid rafts in T-cell activation. EMBO Rep 9: 525-530.

Horn J, Wang X, Reichardt P, Stradal TE, Warnecke N, Simeoni L, Gunzer M, Yablonski D, Schraven B, Kliche S. 2009. Src homology 2-domain containing leukocytespecific phosphoprotein of $76 \mathrm{kDa}$ Is mandatory for TCR-mediated inside-out signaling, but dispensable for CXCR4-mediated LFA-1 activation, adhesion, and migration of T cells. J Immunol 183: 5756-5767.

Houtman JC, Brown PH, Bowden B, Yamaguchi H, Appella E, Samelson LE, Schuck P. 2007. Studying multisite binary and ternary protein interactions by global analysis of isothermal titration calorimetry data in SEDPHAT: Application to adaptor protein complexes in cell signaling. Protein Sci 16: 30-42.

Houtman JC, Higashimoto Y, Dimasi N, Cho S, Yamaguchi H, Bowden B, Regan C, Malchiodi EL, Mariuzza R, Schuck P, et al. 2004. Binding specificity of multiprotein signaling complexes is determined by both cooperative interactions and affinity preferences. Biochemistry 43: 4170-4178.

Houtman JC, Houghtling RA, Barda-Saad M, Toda Y, Samelson LE. 2005. Early phosphorylation kinetics of proteins involved in proximal TCR-mediated signaling pathways. J Immunol 175: 2449-2458.
Houtman JC, Yamaguchi H, Barda-Saad M, Braiman A Bowden B, Appella E, Schuck P, Samelson LE. 2006. Oligomerization of signaling complexes by the multipoint binding of GRB2 to both LAT and SOS1. Nat Struct Mol Biol 13: 798-805.

Hu MC, Qiu WR, Wang X, Meyer CF, Tan TH. 1996. Human HPK1, a novel human hematopoietic progenitor kinase that activates the JNK/SAPK kinase cascade. Genes Dev 10: $2251-2264$.

Hundt M, Harada Y, De Giorgio L, Tanimura N, Zhang W, Altman A. 2009. Palmitoylation-dependent plasma membrane transport but lipid raft-independent signaling by linker for activation of $\mathrm{T}$ cells. J Immunol 183: 1685-1694.

Hundt M, Tabata H, Jeon MS, Hayashi K, Tanaka Y, Krishna R, De Giorgio L, Liu YC, Fukata M, Altman A. 2006. Impaired activation and localization of LAT in anergic $\mathrm{T}$ cells as a consequence of a selective palmitoylation defect. Immunity 24: 513-522.

Hunter T. 2009. Tyrosine phosphorylation: Thirty years and counting. Curr Opin Cell Biol 21: 140-146.

Huse M, Klein LO, Girvin AT, Faraj JM, Li QJ, Kuhns MS, Davis MM. 2007. Spatial and temporal dynamics of $\mathrm{T}$ cell receptor signaling with a photoactivatable agonist. Immunity 27: 76-88.

Ilani T, Vasiliver-Shamis G, Vardhana S, Bretscher A, Dustin ML. 2009. T cell antigen receptor signaling and immunological synapse stability require myosin IIA. Nat Immunol 10: $531-539$.

Irvin BJ, Williams BL, Nilson AE, Maynor HO, Abraham RT. 2000. Pleiotropic contributions of phospholipase C- $\gamma 1$ (PLC- $\gamma 1$ ) to T-cell antigen receptor-mediated signaling: Reconstitution studies of a PLC- $\gamma 1$-deficient Jurkat T-cell line. Mol Cell Biol 20: 9149-9161.

Janes PW, Ley SC, Magee AI. 1999. Aggregation of lipid rafts accompanies signaling via the $\mathrm{T}$ cell antigen receptor. J Cell Biol 147: 447-461.

Jiang Y, Cheng H. 2007. Evidence of LAT as a dual substrate for Lck and Syk in T lymphocytes. Leuk Res 31: 541-545.

June CH, Fletcher MC, Ledbetter JA, Samelson LE. 1990. Increases in tyrosine phosphorylation are detectable before phospholipase $\mathrm{C}$ activation after $\mathrm{T}$ cell receptor stimulation. J Immunol 144: 1591-1599.

Kaizuka Y, Douglass AD, Vardhana S, Dustin ML, Vale RD. 2009. The coreceptor CD2 uses plasma membrane microdomains to transduce signals in T cells. J Cell Biol 185: $521-534$.

Kaizuka Y, Douglass AD, Varma R, Dustin ML, Vale RD. 2007. Mechanisms for segregating $\mathrm{T}$ cell receptor and adhesion molecules during immunological synapse formation in Jurkat T cells. Proc Natl Acad Sci 104: 20296-20301.

Kane LP, Lin J, Weiss A. 2000. Signal transduction by the TCR for antigen. Curr Opin Immunol 12: 242-249.

Kang Q, Yu Y, Pei X, Hughes R, Heck S, Zhang X, Guo X, Halverson G, Mohandas N, An X. 2009. Cytoskeletal protein 4 .1R negatively regulates $\mathrm{T}$-cell activation by inhibiting the phosphorylation of LAT. Blood 113: 6128-6137.

Kenworthy AK. 2008. Have we become overly reliant on lipid rafts? Talking point on the involvement of lipid rafts in T-cell activation. EMBO Rep 9: 531-535. 
Kiefer F, Tibbles LA, Anafi M, Janssen A, Zanke BW, Lassam N, Pawson T, Woodgett JR, Iscove NN. 1996. HPK1, a hematopoietic protein kinase activating the SAPK/JNK pathway. EMBO J 15: 7013-7025.

Koonpaew S, Shen S, Flowers L, Zhang W. 2006. LATmediated signaling in $\mathrm{CD} 4+\mathrm{CD} 25+$ regulatory $\mathrm{T}$ cell development. J Exp Med 203: 119-129.

Koretzky GA, Abtahian F, Silverman MA. 2006. SLP76 and SLP65: Complex regulation of signalling in lymphocytes and beyond. Nat Rev Immunol 6: 67-78.

Krummel MF, Sjaastad MD, Wulfing C, Davis MM. 2000. Differential clustering of CD4 and CD3zeta during T cell recognition. Science 289: 1349-1352.

Ku GM, Yablonski D, Manser E, Lim L, Weiss A. 2001. A PAK1-PIX-PKL complex is activated by the T-cell receptor independent of Nck, Slp-76 and LAT. EMBO J 20: 457-465.

Lahesmaa R, Allsup A, Soderberg C, Jackman J, Findell P, Peltz G. 1995. Modulation of the Grb2-associated protein complex in human $\mathrm{CD} 4+\mathrm{T}$ cells by receptor activation. J Immunol 155: 3815-3822.

Lee KH, Dinner AR, Tu C, Campi G, Raychaudhuri S, Varma R, Sims TN, Burack WR, Wu H, Wang J, et al. 2003. The immunological synapse balances $\mathrm{T}$ cell receptor signaling and degradation. Science 302: 1218-1222.

Lillemeier BF, Mortelmaier MA, Forstner MB, Huppa JB, Groves JT, Davis MM. 2010. TCR and Lat are expressed on separate protein islands on T cell membranes and concatenate during activation. Nat Immunol 11: 90-96.

Lillemeier BF, Pfeiffer JR, Surviladze Z, Wilson BS, Davis MM. 2006. Plasma membrane-associated proteins are clustered into islands attached to the cytoskeleton. Proc Natl Acad Sci 103: 18992-18997.

Lin J, Weiss A. 2001. Identification of the minimal tyrosine residues required for linker for activation of $\mathrm{T}$ cell function. J Biol Chem 276: 29588-29595.

Lin J, Weiss A, Finco TS. 1999. Localization of LAT in glycolipid-enriched microdomains is required for $\mathrm{T}$ cell activation. J Biol Chem 274: 28861-28864.

Lindholm CK, Gylfe E, Zhang W, Samelson LE, Welsh M. 1999. Requirement of the Src homology 2 domain protein Shb for T cell receptor-dependent activation of the interleukin-2 gene nuclear factor for activation of $\mathrm{T}$ cells element in Jurkat T cells. J Biol Chem 274: 28050-28057.

Lindholm CK, Henriksson ML, Hallberg B, Welsh M. 2002. Shb links SLP-76 and Vav with the CD3 complex in Jurkat T cells. Eur J Biochem 269: 3279-3288.

Liou J, Kiefer F, Dang A, Hashimoto A, Cobb MH, Kurosaki T, Weiss A. 2000. HPK1 is activated by lymphocyte antigen receptors and negatively regulates AP-1. Immunity 12: 399-408.

Liu SK, Fang N, Koretzky GA, McGlade CJ. 1999. The hematopoietic-specific adaptor protein Gads functions in T-cell signaling via interactions with the SLP-76 and LAT adaptors. Curr Biol 9: 67-75.

Lorenz U. 2009. SHP-1 and SHP-2 in T cells: Two phosphatases functioning at many levels. Immunol Rev 228: $342-359$.

Lu LF, Rudensky A. 2009. Molecular orchestration of differentiation and function of regulatory T cells. Genes Dev 23: $1270-1282$.
Mingueneau M, Roncagalli R, Gregoire C, Kissenpfennig A, Miazek A, Archambaud C, Wang Y, Perrin P, Bertosio E, Sansoni A, et al. 2009. Loss of the LAT adaptor converts antigen-responsive $\mathrm{T}$ cells into pathogenic effectors that function independently of the T cell receptor. Immunity 31: 197-208.

Miyaji M, Kortum RL, Surana R, Li W, Woolard KD, Simpson RM, Samelson LE, Sommers CL. 2009. Genetic evidence for the role of Erk activation in a lymphoproliferative disease of mice. Proc Natl Acad Sci 106: 14502-14507.

Monks CR, Freiberg BA, Kupfer H, Sciaky N, Kupfer A. 1998. Three-dimensional segregation of supramolecular activation clusters in T cells. Nature 395: 82-86.

Montixi C, Langlet C, Bernard AM, Thimonier J, Dubois C, Wurbel MA, Chauvin JP, Pierres M, He HT. 1998. Engagement of $\mathrm{T}$ cell receptor triggers its recruitment to low-density detergent-insoluble membrane domains. EMBO J 17: 5334-5348.

Mossman KD, Campi G, Groves JT, Dustin ML. 2005. Altered TCR signaling from geometrically repatterned immunological synapses. Science 310: 1191-1193.

Munro S. 2003. Lipid rafts: Elusive or illusive? Cell 115: 377-388.

Murphy MA, Schnall RG, Venter DJ, Barnett L, Bertoncello I, Thien CB, Langdon WY, Bowtell DD. 1998. Tissue hyperplasia and enhanced T-cell signalling via ZAP-70 in c-Cbl-deficient mice. Mol Cell Biol 18: 4872-4882.

Musci MA, Hendricks-Taylor LR, Motto DG, Paskind M, Kamens J, Turck CW, Koretzky GA. 1997. Molecular cloning of SLAP-130, an SLP-76-associated substrate of the T cell antigen receptor-stimulated protein tyrosine kinases. J Biol Chem 272: 11674-11677.

Myers MD, Sosinowski T, Dragone LL, White C, Band H, Gu H, Weiss A. 2006. Src-like adaptor protein regulates TCR expression on thymocytes by linking the ubiquitin ligase c-Cbl to the TCR complex. Nat Immunol 7: 57-66.

Nguyen K, Sylvain NR, Bunnell SC. 2008. T cell costimulation via the integrin VLA-4 inhibits the actin-dependent centralization of signaling microclusters containing the adaptor SLP-76. Immunity 28: 810-821.

Nunez-Cruz S, Aguado E, Richelme S, Chetaille B, Mura AM, Richelme M, Pouyet L, Jouvin-Marche E, Xerri L, Malissen B, et al. LAT regulates gammadelta T cell homeostasis and differentiation. Nat Immunol 4: 999-1008.

Oh-hora M. 2009. Calcium signaling in the development and function of T-lineage cells. Immunol Rev 231: 210-224.

Ott VL, Tamir I, Niki M, Pandolfi PP, Cambier JC. 2002. Downstream of kinase, p62(dok), is a mediator of Fc $\gamma$ IIB inhibition of Fc epsilon RI signaling. J Immunol 168: $4430-4439$.

Oya K, Wang J, Watanabe Y, Koga R, Watanabe T. 2003. Appearance of the LAT protein at an early stage of B-cell development and its possible role. Immunology 109: 351-359.

Paz PE, Wang S, Clarke H, Lu X, Stokoe D, Abo A. 2001. Mapping the Zap-70 phosphorylation sites on LAT (linker for activation of $\mathrm{T}$ cells) required for recruitment and activation of signalling proteins in T cells. Biochem J 356: 461-471. 
L. Balagopalan et al.

Perez-Villar JJ, Whitney GS, Sitnick MT, Dunn RJ, Venkatesan S, O’Day K, Schieven GL, Lin TA, Kanner SB. 2002. Phosphorylation of the linker for activation of T-cells by Itk promotes recruitment of Vav. Biochemistry 41: $10732-10740$.

Quilliam LA. 2007. New insights into the mechanisms of SOS activation. Sci STKE 2007: pe67.

Readinger JA, Mueller KL, Venegas AM, Horai R, Schwartzberg PL. 2009. Tec kinases regulate T-lymphocyte development and function: New insights into the roles of Itk and Rlk/Txk. Immunol Rev 228: 93-114.

Rellahan BL, Graham LJ, Tysgankov AY, DeBell KE, Veri MC Noviello C, Bonvini E. 2003. A dynamic constitutive and inducible binding of c-Cbl by PLC $\gamma 1 \mathrm{SH} 3$ and $\mathrm{SH} 2$ domains (negatively) regulates antigen receptor-induced PLCy1 activation in lymphocytes. Exp Cell Res 289: 184-194.

Reynolds LF, Smyth LA, Norton T, Freshney N, Downward J, Kioussis D, Tybulewicz VL. 2002. Vav1 transduces T cell receptor signals to the activation of phospholipase C- $\gamma 1$ via phosphoinositide 3-kinase-dependent and -independent pathways. J Exp Med 195: 1103-1114.

Rhee SG, Bae YS. 1997. Regulation of phosphoinositidespecific phospholipase C isozymes. J Biol Chem 272: 15045-15048

Rivero-Lezcano OM, Sameshima JH, Marcilla A, Robbins KC. 1994. Physical association between Src homology 3 elements and the protein product of the c-cbl protooncogene. J Biol Chem 269: 17363-17366.

Rohatgi R, Nollau P, Ho HY, Kirschner MW, Mayer BJ. 2001. Nck and phosphatidylinositol 4,5-bisphosphate synergistically activate actin polymerization through the $\mathrm{N}$ WASP-Arp2/3 pathway. J Biol Chem 276: 26448-26452.

Samelson LE. 2002. Signal transduction mediated by the T cell antigen receptor: The role of adapter proteins. Annu Rev Immunol 20: 371-394.

Sangani D, Venien-Bryan C, Harder T. 2009. Phosphotyrosine-dependent in vitro reconstitution of recombinant LAT-nucleated multiprotein signalling complexes on liposomes. Mol Membr Biol 26: 159-170.

Seminario MC, Bunnell SC. 2008. Signal initiation in T-cell receptor microclusters. Immunol Rev 221: 90-106.

Serrano CJ, Graham L, DeBell K, Rawat R, Veri MC, Bonvini E, Rellahan BL, Reischl IG. 2005. A new tyrosine phosphorylation site in PLC $\gamma$ 1: The role of tyrosine 775 in immune receptor signaling. J Immunol 174: 6233-6237.

Shan X, Balakir R, Criado G, Wood JS, Seminario MC, Madrenas J, Wange RL. 2001. Zap-70-independent $\mathrm{Ca}(2+)$ mobilization and Erk activation in Jurkat T cells in response to T-cell antigen receptor ligation. Mol Cell Biol 21: 7137-7149.

Shen R, Ouyang YB, Qu CK, Alonso A, Sperzel L, Mustelin T, Kaplan MH, Feng GS. 2002. Grap negatively regulates T-cell receptor-elicited lymphocyte proliferation and interleukin-2 induction. Mol Cell Biol 22: 3230-3236.

Shen S, Zhu M, Lau J, Chuck M, Zhang W. 2009. The essential role of LAT in thymocyte development during transition from the double-positive to single-positive stage. J Immunol 182: 5596-5604.

Shim EK, Moon CS, Lee GY, Ha YJ, Chae SK, Lee JR. 2004. Association of the Src homology 2 domain-containing leukocyte phosphoprotein of $76 \mathrm{kD}$ (SLP-76) with the p85 subunit of phosphoinositide 3-kinase. FEBS Lett 575: 35-40.

Shui JW, Boomer JS, Han J, Xu J, Dement GA, Zhou G, Tan TH. 2007. Hematopoietic progenitor kinase 1 negatively regulates $\mathrm{T}$ cell receptor signaling and $\mathrm{T}$ cell-mediated immune responses. Nat Immunol 8: 84-91.

Sieh M, Batzer A, Schlessinger J, Weiss A. 1994. GRB2 and phospholipase C- $\gamma 1$ associate with a 36- to 38-kilodalton phosphotyrosine protein after T-cell receptor stimulation. Mol Cell Biol 14: 4435-4442.

Sigismund S, Woelk T, Puri C, Maspero E, Tacchetti C, Transidico P, Di Fiore PP, Polo S. 2005. Clathrin-independent endocytosis of ubiquitinated cargos. Proc Natl Acad Sci 102: 2760-2765.

Singer AL, Bunnell SC, Obstfeld AE, Jordan MS, Wu JN, Myung PS, Samelson LE, Koretzky GA. 2004. Roles of the proline-rich domain in SLP-76 subcellular localization and T cell function. J Biol Chem 279: 15481-15490.

Sommers CL, Lee J, Steiner KL, Gurson JM, DePersis CL, El-Khoury D, Fuller CL, Shores EW, Love PE, Samelson LE. 2005. Mutation of the phospholipase C- $\gamma 1$-binding site of LAT affects both positive and negative thymocyte selection. J Exp Med 201: 1125-1134.

Sommers CL, Samelson LE, Love PE. 2004. LAT: A T lymphocyte adapter protein that couples the antigen receptor to downstream signaling pathways. Bioessays 26: 61-67.

Sommers CL, Menon RK, Grinberg A, Zhang W, Samelson LE, Love PE. 2001. Knock-in mutation of the distal four tyrosines of linker for activation of T cells blocks murine T cell development. J Exp Med 194: 135-142.

Sommers CL, Park CS, Lee J, Feng C, Fuller CL, Grinberg A, Hildebrand JA, Lacana E, Menon RK, Shores EW, et al. 2002. A LAT mutation that inhibits T cell development yet induces lymphoproliferation. Science 296: 2040-2043.

Stoica B, DeBell KE, Graham L, Rellahan BL, Alava MA, Laborda J, Bonvini E. 1998. The amino-terminal Src homology 2 domain of phospholipase $\mathrm{C} \gamma 1$ is essential for TCR-induced tyrosine phosphorylation of phospholipase C $\gamma$ 1. J Immunol 160: 1059-1066.

Tamir I, Stolpa JC, Helgason CD, Nakamura K, Bruhns P, Daeron M, Cambier JC. 2000. The RasGAP-binding protein p62dok is a mediator of inhibitory Fc $\gamma$ RIIB signals in B cells. Immunity 12: 347-358.

Tanimura N, Nagafuku M, Liddicoat DR, Hamaoka T, Kosugi A. 2003a. Analysis of the mobility of signaling molecules in lymphocytes using fluorescence photobleaching techniques. Sci STKE 2003: pl10.

Tanimura N, Nagafuku M, Minaki Y, Umeda Y, Hayashi F, Sakakura J, Kato A, Liddicoat DR, Ogata M, Hamaoka T, et al. 2003b. Dynamic changes in the mobility of LAT in aggregated lipid rafts upon T cell activation. J Cell Biol 160: 125-135.

Tanimura N, Saitoh S, Kawano S, Kosugi A, Miyake K. 2006. Palmitoylation of LAT contributes to its subcellular localization and stability. Biochem Biophys Res Commun 341: 1177-1183.

Trub T, Frantz JD, Miyazaki M, Band H, Shoelson SE. 1997. The role of a lymphoid-restricted, Grb2-like $\mathrm{SH} 3-\mathrm{SH} 2-\mathrm{SH} 3$ protein in $\mathrm{T}$ cell receptor signaling. J Biol Chem 272: 894-902. 
Varma R, Campi G, Yokosuka T, Saito T, Dustin ML. 2006. T cell receptor-proximal signals are sustained in peripheral microclusters and terminated in the central supramolecular activation cluster. Immunity 25: 117-127.

Wang X. 2009. Cre transgenic mouse lines. Methods Mol Biol 561: 265-273.

Wang H, Wei B, Bismuth G, Rudd CE. 2009. SLP-76-ADAP adaptor module regulates LFA-1 mediated costimulation and T cell motility. Proc Natl Acad Sci 106: 12436-12441.

Wang Y, Kissenpfennig A, Mingueneau M, Richelme S, Perrin P, Chevrier S, Genton C, Lucas B, DiSanto JP, Acha-Orbea H, et al. 2008. Th2 lymphoproliferative disorder of LatY136F mutant mice unfolds independently of TCR-MHC engagement and is insensitive to the action of Foxp3 + regulatory T cells. J Immunol 180: 1565-1575.

Wange RL. 2000. LAT, the linker for activation of T cells: A bridge between $\mathrm{T}$ cell-specific and general signaling pathways. Sci STKE 2000: RE1.

Weber JR, Bell GM, Han MY, Pawson T, Imboden JB. 1992. Association of the tyrosine kinase LCK with phospholipase $\mathrm{C}-\boldsymbol{\gamma} 1$ after stimulation of the $\mathrm{T}$ cell antigen receptor. J Exp Med 176: 373-379.

Weber JR, Orstavik S, Torgersen KM, Danbolt NC, Berg SF Ryan JC, Tasken K, Imboden JB, Vaage JT. 1998. Molecular cloning of the cDNA encoding p36, a tyrosinephosphorylated adaptor protein selectively expressed by T cells and natural killer cells. J Exp Med 187: 1157-1161.

Weissman AM. 2001. Themes and variations on ubiquitylation. Nat Rev Mol Cell Biol 2: 169-178.

Wilson BS, Pfeiffer JR, Surviladze Z, Gaudet EA, Oliver JM. 2001. High resolution mapping of mast cell membranes reveals primary and secondary domains of $\mathrm{Fc}$ (epsilon)RI and LAT. J Cell Biol 154: 645-658.

Wittekind M, Mapelli C, Farmer BT 2nd, Suen KL, Goldfarb V, Tsao J, Lavoie T, Barbacid M, Meyers CA, Mueller L. 1994. Orientation of peptide fragments from Sos proteins bound to the N-terminal SH3 domain of Grb2 determined by NMR spectroscopy. Biochemistry 33: 13531-13539.

Wulfing C, Davis MM. 1998. A receptor/cytoskeletal movement triggered by costimulation during $\mathrm{T}$ cell activation. Science 282: 2266-2269.

Wunderlich L, Farago A, Downward J, Buday L. 1999. Association of Nck with tyrosine-phosphorylated SLP-76 in activated T lymphocytes. Eur J Immunol 29: 1068-1075.

Yablonski D, Kadlecek T, Weiss A. 2001. Identification of a phospholipase C- $\gamma 1$ (PLC- $\gamma 1$ ) SH3 domain-binding site in SLP-76 required for T-cell receptor-mediated activation of PLC- $\gamma 1$ and NFAT. Mol Cell Biol 21: 4208-4218.

Yablonski D, Kuhne MR, Kadlecek T, Weiss A. 1998. Uncoupling of nonreceptor tyrosine kinases from PLC- $\gamma 1$ in an SLP-76-deficient T cell. Science 281: 413-416.

Yamasaki S, Nishida K, Hibi M, Sakuma M, Shiina R, Takeuchi A, Ohnishi H, Hirano T, Saito T. 2001. Docking protein Gab2 is phosphorylated by ZAP-70 and negatively regulates $\mathrm{T}$ cell receptor signaling by recruitment of inhibitory molecules. J Biol Chem 276: 45175-45183.

Yamasaki S, Nishida K, Sakuma M, Berry D, McGlade CJ, Hirano T, Saito T. 2003. Gads/Grb2-mediated association with LAT is critical for the inhibitory function of Gab2 in T cells. Mol Cell Biol 23: 2515-2529.

Yasuda T, Bundo K, Hino A, Honda K, Inoue A, Shirakata M, Osawa M, Tamura T, Nariuchi $\mathrm{H}$, Oda $\mathrm{H}$, et al. 2007. Dok-1 and Dok-2 are negative regulators of $\mathrm{T}$ cell receptor signaling. Int Immunol 19: 487-495.

Yokosuka T, Kobayashi W, Sakata-Sogawa K, Takamatsu M, Hashimoto-Tane A, Dustin ML, Tokunaga M, Saito T. 2008. Spatiotemporal regulation of T cell costimulation by TCR-CD28 microclusters and protein kinase $\mathrm{C}$ theta translocation. Immunity 29: 589-601.

Yokosuka T, Sakata-Sogawa K, Kobayashi W, Hiroshima M, Hashimoto-Tane A, Tokunaga M, Dustin ML, Saito T. 2005. Newly generated T cell receptor microclusters initiate and sustain $\mathrm{T}$ cell activation by recruitment of Zap70 and SLP-76. Nat Immunol 6: 1253-1262.

Zeng R, Cannon JL, Abraham RT, Way M, Billadeau DD, Bubeck-Wardenberg J, Burkhardt JK. 2003. SLP-76 coordinates Nck-dependent Wiskott-Aldrich syndrome protein recruitment with Vav-1/Cdc42-dependent Wiskott-Aldrich syndrome protein activation at the $\mathrm{T}$ cell-APC contact site. J Immunol 171: 1360-1368.

Zhang W, Irvin BJ, Trible RP, Abraham RT, Samelson LE. 1999a. Functional analysis of LAT in TCR-mediated signaling pathways using a LAT-deficient Jurkat cell line. Int Immunol 11: 943-950.

Zhang W, Sloan-Lancaster J, Kitchen J, Trible RP, Samelson LE. 1998a. LAT: The ZAP-70 tyrosine kinase substrate that links $\mathrm{T}$ cell receptor to cellular activation. Cell 92: $83-92$.

Zhang W, Sommers CL, Burshtyn DN, Stebbins CC, DeJarnette JB, Trible RP, Grinberg A, Tsay HC, Jacobs HM, Kessler CM, et al. 1999b. Essential role of LAT in $\mathrm{T}$ cell development. Immunity 10: 323-332.

Zhang W, Trible RP, Samelson LE. 1998b. LAT palmitoylation: Its essential role in membrane microdomain targeting and tyrosine phosphorylation during $\mathrm{T}$ cell activation. Immunity 9: 239-246.

Zhang W, Trible RP, Zhu M, Liu SK, McGlade CJ, Samelson LE. 2000. Association of Grb2, Gads, and phospholipase C- $\gamma 1$ with phosphorylated LAT tyrosine residues. Effect of LAT tyrosine mutations on $\mathrm{T}$ cell antigen receptormediated signaling. J Biol Chem 275: 23355-23361.

Zhu M, Janssen E, Zhang W. 2003. Minimal requirement of tyrosine residues of Linker for Activation of T Cells in TCR signaling and thymocyte development. J Immunol 170: 325-333.

Zhu M, Shen S, Liu Y, Granillo O, Zhang W. 2005. Cutting Edge: Localization of linker for activation of $\mathrm{T}$ cells to lipid rafts is not essential in T cell activation and development. J Immunol 174: 31-35. 


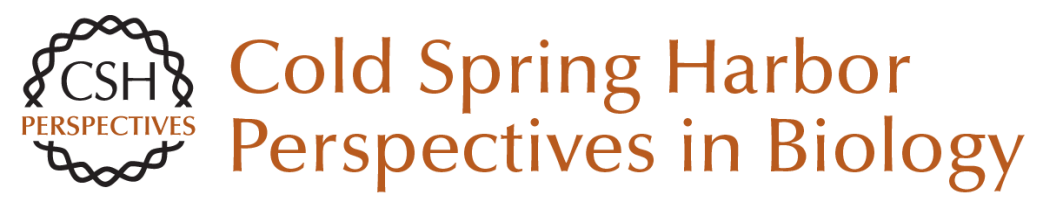

\section{The LAT Story: A Tale of Cooperativity, Coordination, and Choreography}

Lakshmi Balagopalan, Nathan P. Coussens, Eilon Sherman, Lawrence E. Samelson and Connie L. Sommers

Cold Spring Harb Perspect Biol 2010; doi: 10.1101/cshperspect.a005512 originally published online July 7, 2010

Subject Collection Immunoreceptor Signaling

The Coordination of T-cell Function by

Serine/Threonine Kinases

David Finlay and Doreen Cantrell

ITAM-mediated Signaling by the T-Cell Antigen Receptor

Paul E. Love and Sandra M. Hayes

Coordination of Receptor Signaling in Multiple Hematopoietic Cell Lineages by the Adaptor

Protein SLP-76

Martha S. Jordan and Gary A. Koretzky

The Cytoskeleton Coordinates the Early Events of B-cell Activation

Naomi E. Harwood and Facundo D. Batista

An Enigmatic Tail of CD28 Signaling Jonathan S. Boomer and Jonathan M. Green

Mediation of T-Cell Activation by Actin Meshworks

Peter Beemiller and Matthew F. Krummel
Perspectives for Computer Modeling in the Study of T Cell Activation Jesse Coward, Ronald N. Germain and Grégoire Altan-Bonnet

Structural Biology of the T-cell Receptor: Insights into Receptor Assembly, Ligand Recognition, and Initiation of Signaling

Kai W. Wucherpfennig, Etienne Gagnon, Melissa J. Call, et al.

Src-family and Syk Kinases in Activating and

Inhibitory Pathways in Innate Immune Cells:

Signaling Cross Talk Clifford A. Lowell

The LAT Story: A Tale of Cooperativity, Coordination, and Choreography Lakshmi Balagopalan, Nathan P. Coussens, Eilon Sherman, et al.

Antigen Receptor Signaling to NF- $\mathrm{KB}$ via CARMA1, BCL10, and MALT1 Margot Thome, Jean Enno Charton, Christiane Pelzer, et al.

It's All About Change: The Antigen-driven Initiation of B-Cell Receptor Signaling Wanli Liu, Hae Won Sohn, Pavel Tolar, et al.

For additional articles in this collection, see http://cshperspectives.cshlp.org/cgi/collection/

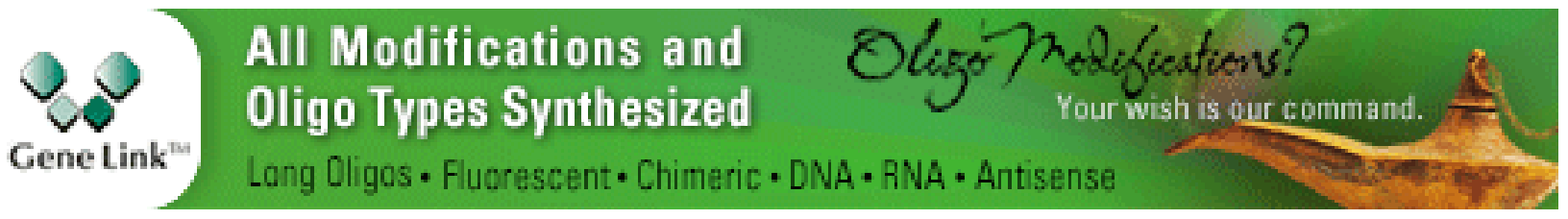

Copyright @ 2010 Cold Spring Harbor Laboratory Press; all rights reserved 
T-Cell Signaling Regulated by the Tec Family

Kinase, Itk

Amy H. Andreotti, Pamela L. Schwartzberg, Raji E. Joseph, et al.

Lipid Signaling in T-Cell Development and

Function

Yina H. Huang and Karsten Sauer
ZAP-70: An Essential Kinase in T-cell Signaling Haopeng Wang, Theresa A. Kadlecek, Byron B. Au-Yeung, et al.

Understanding the Structure and Function of the Immunological Synapse

Michael L. Dustin, Arup K. Chakraborty and Andrey S. Shaw

For additional articles in this collection, see http://cshperspectives.cshlp.org/cgi/collection/

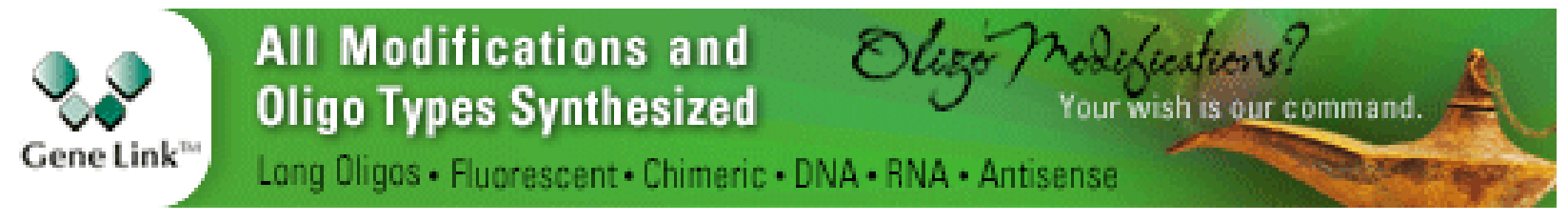

Copyright @ 2010 Cold Spring Harbor Laboratory Press; all rights reserved 